\title{
HIV-1 and Amyloid Beta Remodel Proteome of Brain Endothelial Extracellular Vesicles
}

\author{
Ibolya E. András, Brice B. Sewell $\mathbb{D}$ and Michal Toborek * $\mathbb{D}$ \\ Department of Biochemistry and Molecular Biology, University of Miami School of Medicine, Miami, \\ FL 33136-1019, USA; IAndras@med.miami.edu (I.E.A.); bbs53@miami.edu (B.B.S.) \\ * Correspondence: mtoborek@med.miami.edu
}

Received: 11 March 2020; Accepted: 7 April 2020; Published: 15 April 2020

\begin{abstract}
Amyloid beta $(\mathrm{A} \beta)$ depositions are more abundant in HIV-infected brains. The blood-brain barrier, with its backbone created by endothelial cells, is assumed to be a core player in A $\beta$ homeostasis and may contribute to $A \beta$ accumulation in the brain. Exposure to HIV increases shedding of extracellular vesicles (EVs) from human brain endothelial cells and alters EV-A $\beta$ levels. EVs carrying various cargo molecules, including a complex set of proteins, can profoundly affect the biology of surrounding neurovascular unit cells. In the current study, we sought to examine how exposure to HIV, alone or together with $\mathrm{A} \beta$, affects the surface and total proteomic landscape of brain endothelial EVs. By using this unbiased approach, we gained an unprecedented, high-resolution insight into these changes. Our data suggest that HIV and $\mathrm{A} \beta$ profoundly remodel the proteome of brain endothelial EVs, altering the pathway networks and functional interactions among proteins. These events may contribute to the EV-mediated amyloid pathology in the HIV-infected brain and may be relevant to HIV-1-associated neurocognitive disorders.
\end{abstract}

Keywords: HIV-1; amyloid beta; extracellular vesicles; blood-brain barrier

\section{Introduction}

HIV-infected brains tend to have enhanced amyloid beta (A $\beta)$ deposition [1-6], mostly in the perivascular space [3,7-9]. Indeed, the blood-brain barrier (BBB) is thought to be a key player in the brain's $A \beta$ homeostasis [10]. It is now widely accepted that extracellular vesicles (EVs) may also be important in $A \beta$ pathology [11-17]. Our earlier work has shown that HIV can increase the release of brain endothelial EVs and alter EV-A $\beta$ levels. Moreover, brain endothelial cell-derived EVs can transfer $A \beta$ to other cells of the neurovascular unit [18]. EVs carry specific cargo molecules, including a complex set of proteins, which can be transferred to the neighboring cells and affect their biology. Some of these proteins are on the EV surface. The surface proteins may allow for selective EV uptake by the recipient cells, like in the case of receptor-mediated endocytosis. Total proteomics can give detailed information on the EV protein cargo overall. Surface proteomics could indicate the "address" of a targeted delivery, while total proteomics would represent the delivered "package."

In this work, we investigated how exposure to HIV, alone and together with $\mathrm{A} \beta$, impacts the surface and total proteomic landscape of EVs from human brain microvascular endothelial cells (HBMEC-EVs). By using this unbiased strategy, we obtained a complex, high-resolution insight into these changes. 


\section{Results}

2.1. Extracellular Vesicles from Human Brain Microvascular Endothelial Cells (HBMEC-EVs) Are Enriched with the Major EV Markers

At first, we examined whether proteins that are frequently identified in EVs/exosomes from various sources can be found in our isolated HBMEC-EVs. Based on the ExoCarta EV proteomics database from different human cell types that have been isolated using different approaches [19,20], we compiled the list of 100 marker proteins that are most often present on EVs (Table 1). The surface HBMEC-EV proteome, which contained a total of 283 identified proteins, included 62 of the top 100 ExoCarta EV markers (Figure 1A, Table 1). In addition, the total HBMEC-EV proteome, which contained 501 identified proteins, included 80 of such markers (Figure 1B, Table 1). These results demonstrate that our HBMEC-EV isolation was highly enriched with known EV markers.

A

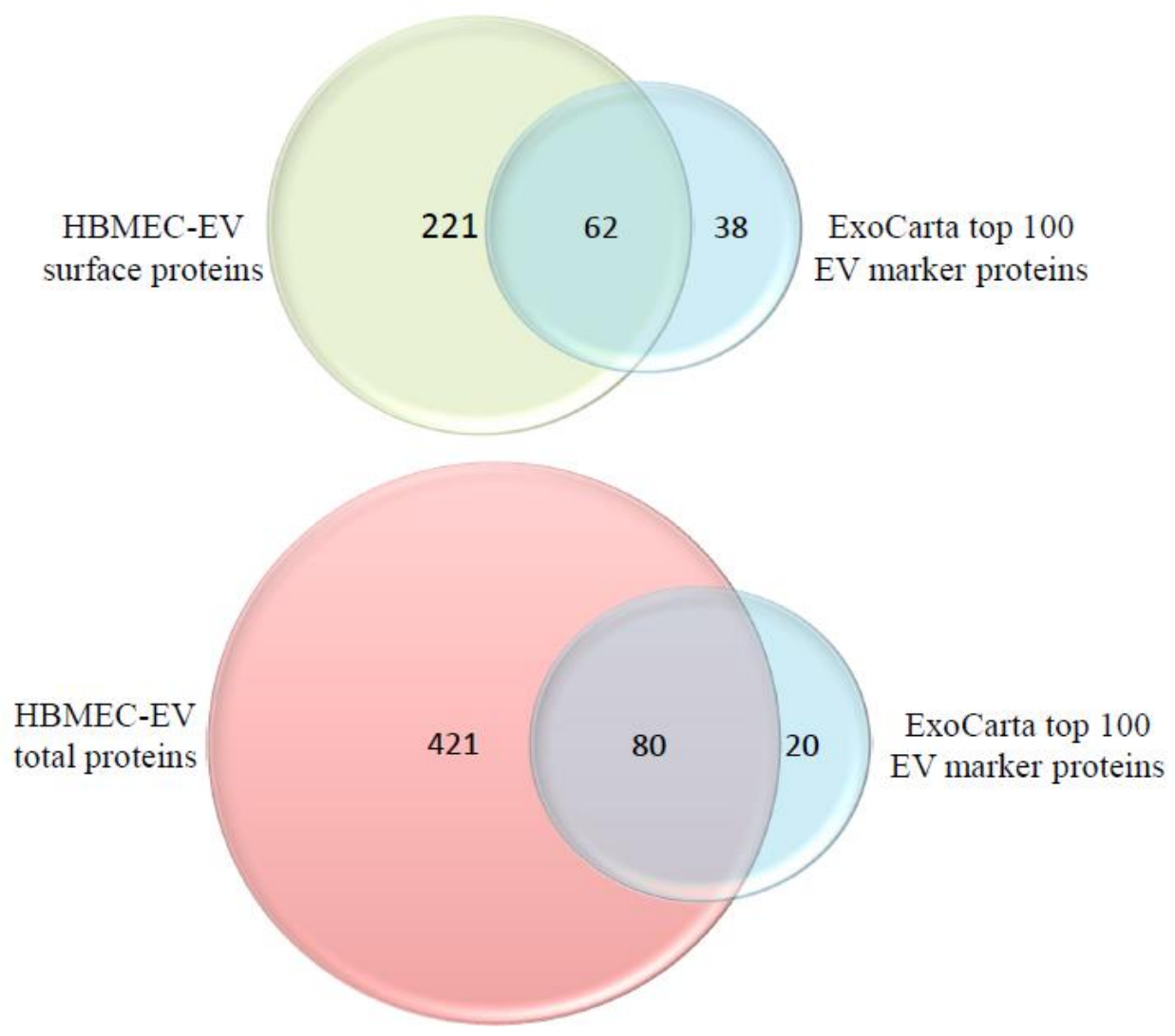

Figure 1. Cont. 
C EV Surface proteome

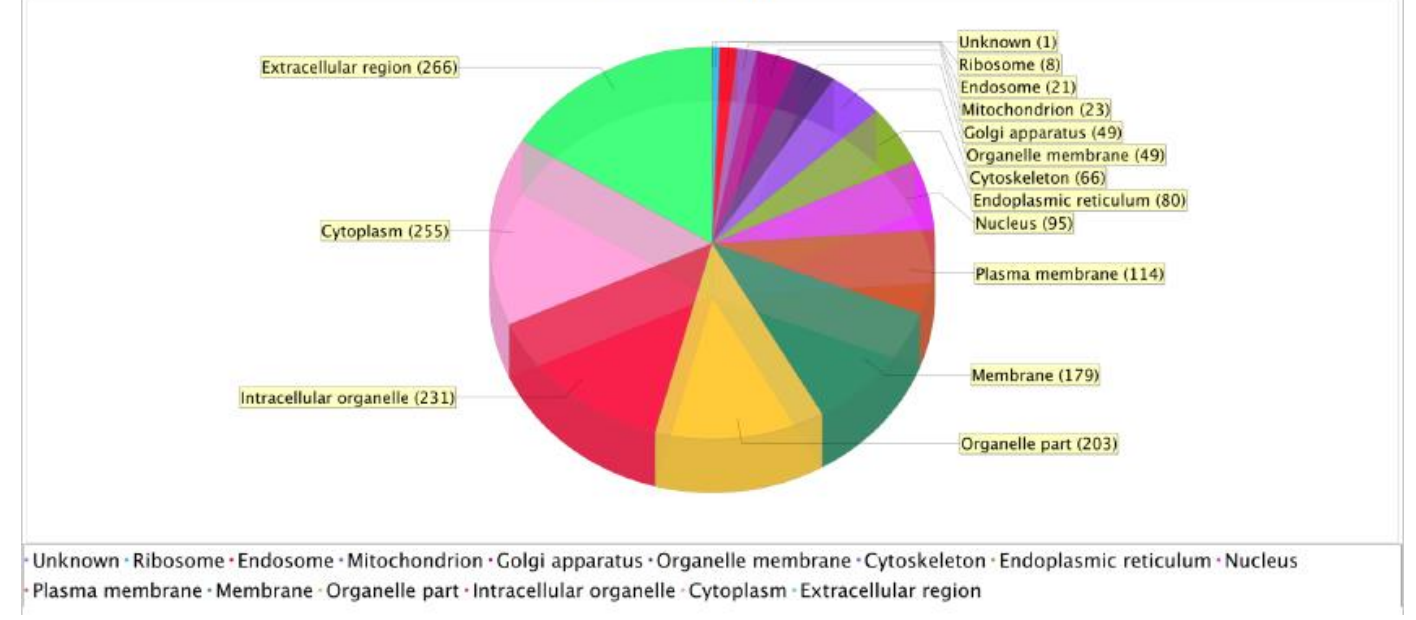

D EV Total proteome

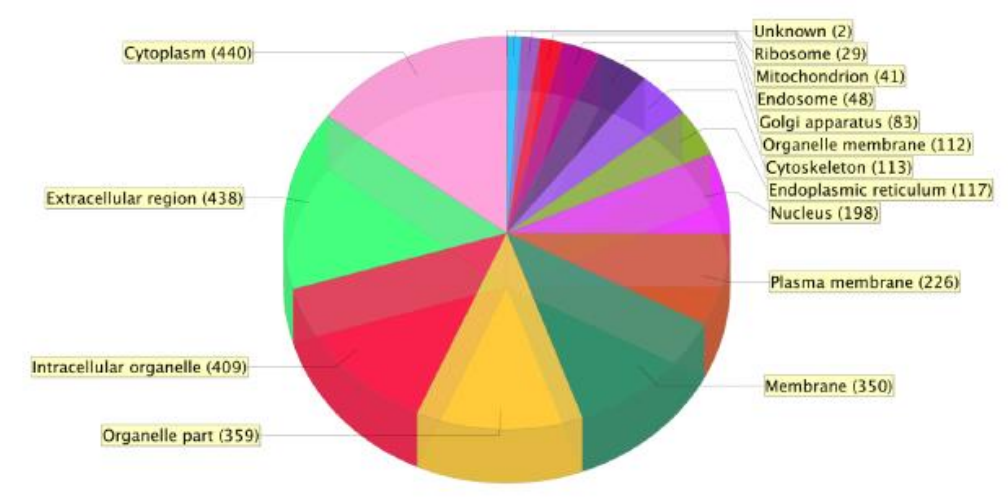

- Unknown - Ribosome - Mitochondrion - Endosome - Golgi apparatus · Organelle membrane · Cytoskeleton · Endoplasmic reticulum · Nucleus - Plasma membrane - Membrane - Organelle part - Intracellular organelle - Extracellular region -Cytoplasm

Figure 1. Extracellular vesicle (EV)-specific markers in the surface and total proteomes of human brain microvascular endothelial cells (HBMEC)-derived EVs. Venn diagram showing the overlap between the HBMEC-EV surface proteome (283 proteins) (A) or the HBMEC-EV total proteome (501 proteins) (B) and the top $100 \mathrm{EV}$ marker proteins from ExoCarta. Cellular component enrichment of the identified surface (C) and total (D) EV proteomes. The identified EV proteins were enriched for cellular component using the Scaffold software.

\subsection{Cellular Component Enrichment of the Identified Surface and Total EV Proteins}

Using the Scaffold software, we next evaluated the HBMEC-EV proteins according to their known cellular localization. This approach may indicate the parent cellular compartment origin of the identified HBMEC-EV proteins. The majority of the HBMEC-EV surface proteins were extracellular region proteins, followed by cytoplasmic, intracellular organelle, membrane, nuclear, endoplasmic reticulum, cytoskeleton, Golgi, mitochondrial, endosomal, ribosomal proteins, and one unknown protein (Figure 1C). For the total HBMEC-EV proteome, the majority of proteins were cytoplasmic and extracellular region proteins (Figure 1D).

\subsection{HIV and Aß Exposure Results in Unique HBMEC-EV Proteome Signatures}

We next focused on the unique proteins induced by the exposure to HIV and A $\beta$. Comparison of the control vs. HIV surface HBMEC-EV proteomes identified 112 unique proteins in the control and 
three unique proteins in the HIV group (Figure 2A). By contrast, a similar comparison for the total proteome identified only three unique proteins in the control and as many as 259 unique proteins in the HIV group (Figure 2B). Comparison of the surface proteome between the HIV vs. HIV+A $\beta$ groups identified six unique proteins in the HIV group and 116 unique proteins in the HIV+A $\beta$ group (Figure 2C). Finally, analysis of the total proteome revealed 28 unique proteins in the HIV group and 201 unique proteins in the HIV $+\mathrm{A} \beta$ group (Figure 2D). A list of these unique proteins is provided in Tables 2 and 3 for the surface and total proteomes, respectively.

A

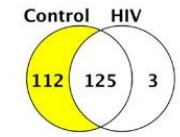

Surface proteome
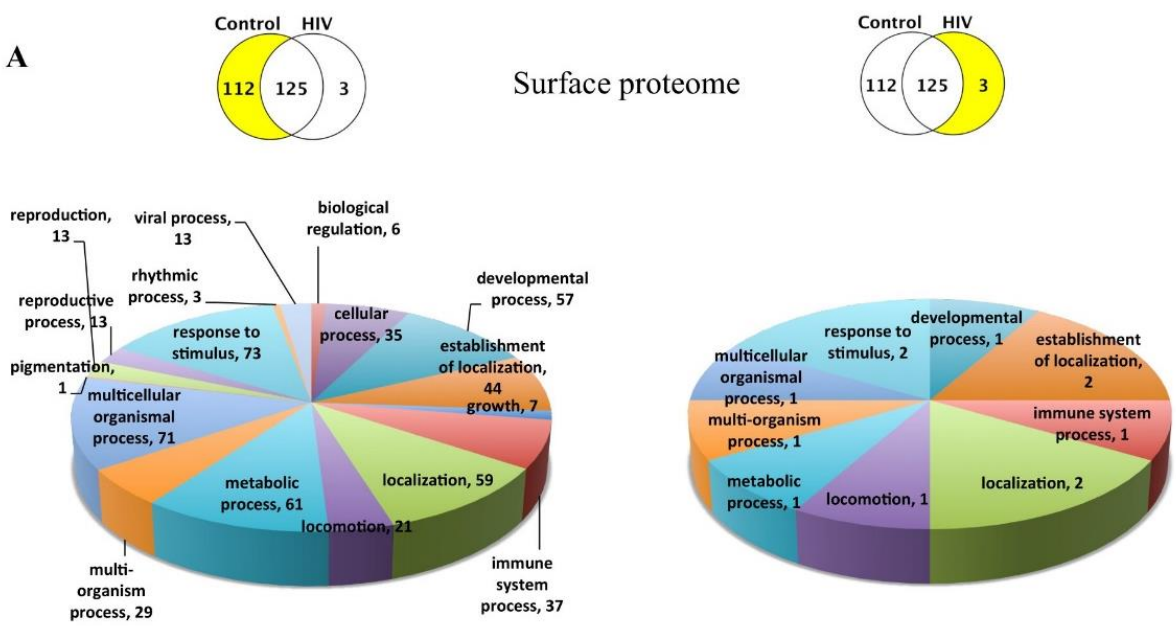

B

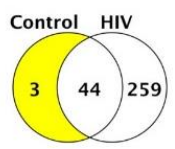

Total proteome
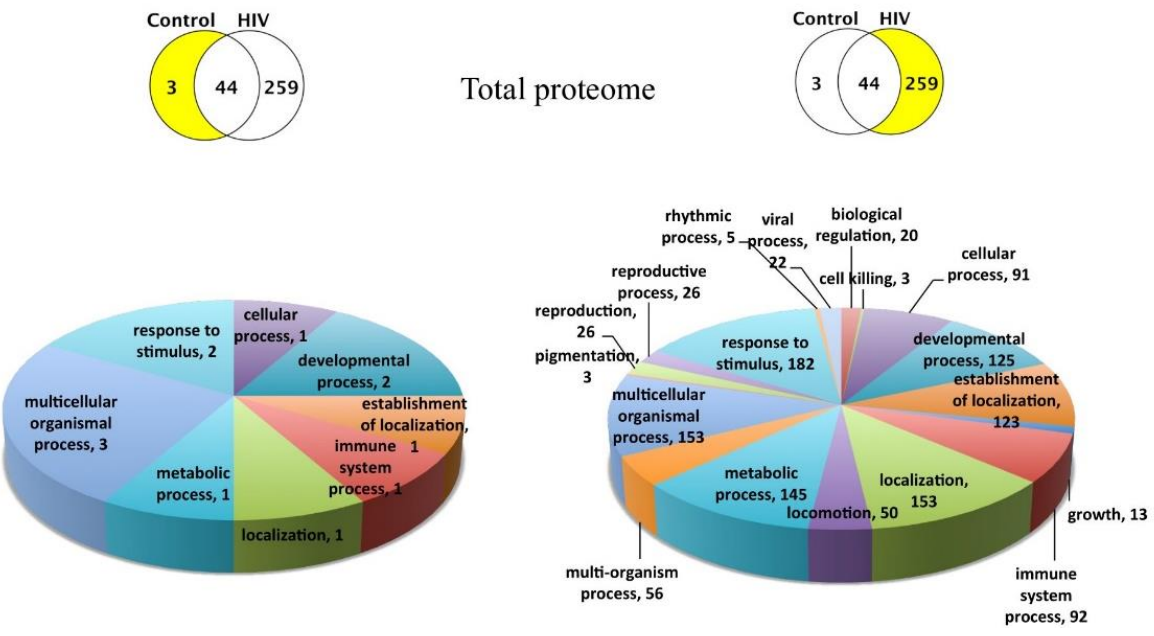

C

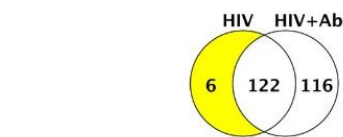

Surface proteome
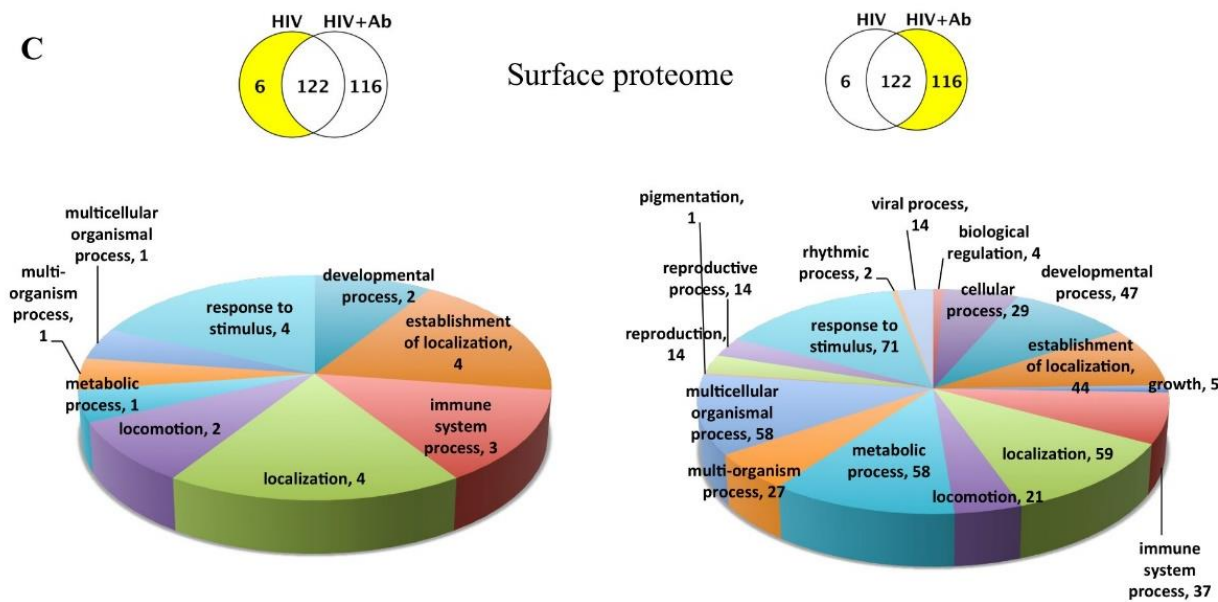

Figure 2. Cont. 
D
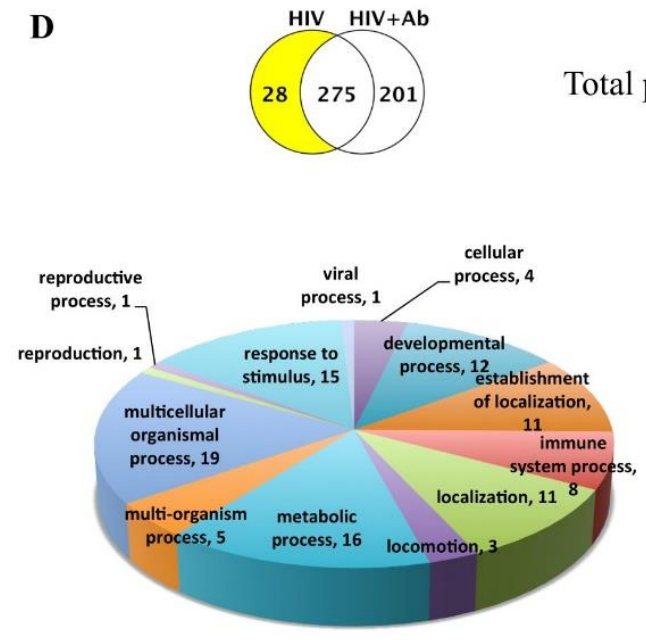

Total proteome
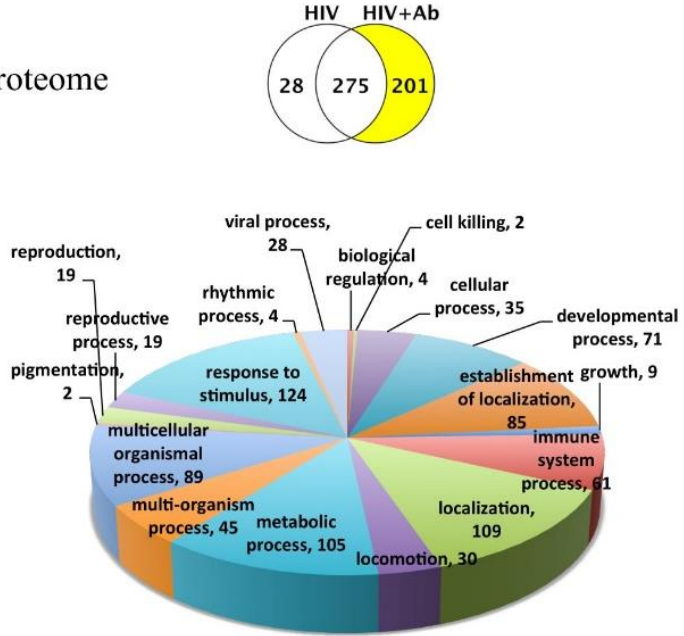

E

EV unique Surface proteins

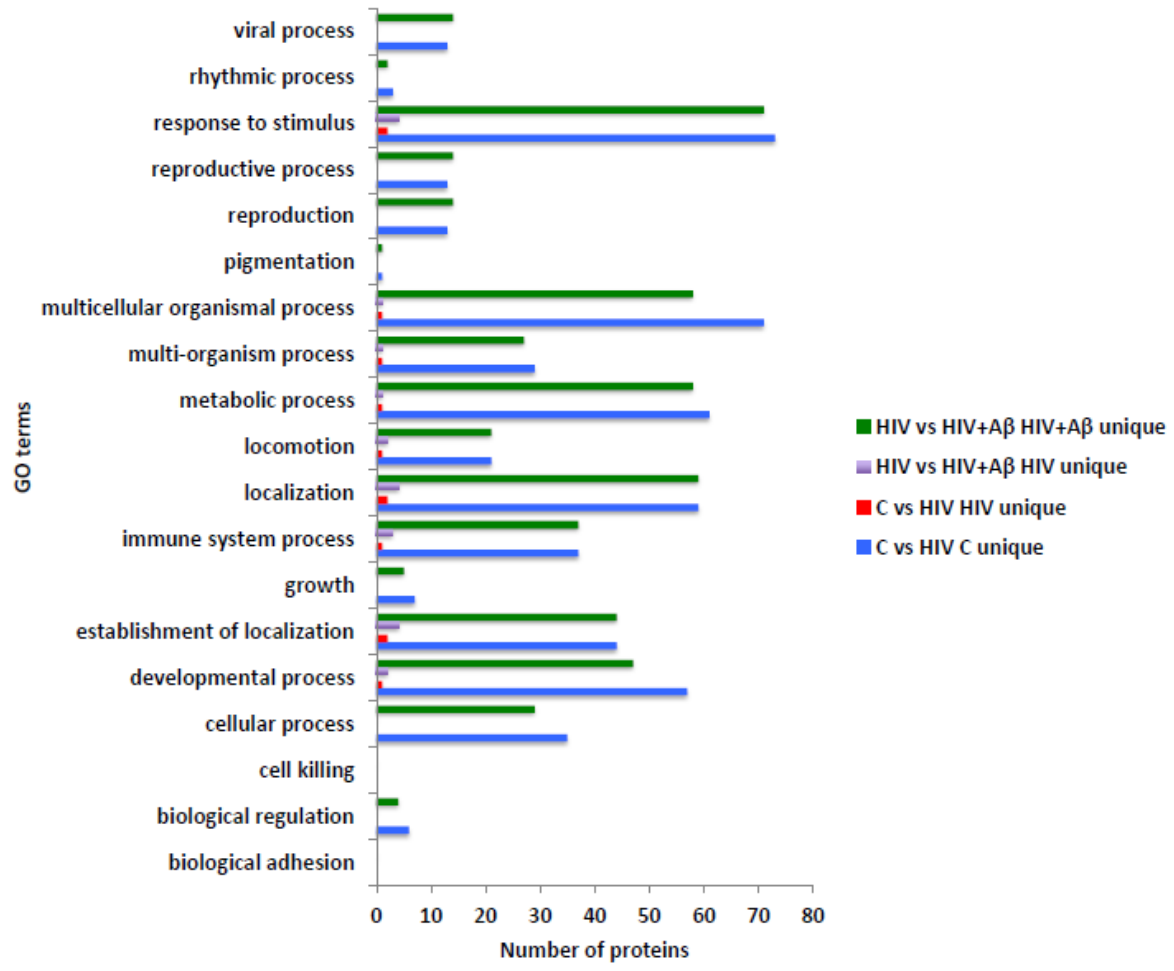

Figure 2. Cont. 
$\mathbf{F}$ EV unique Total proteins

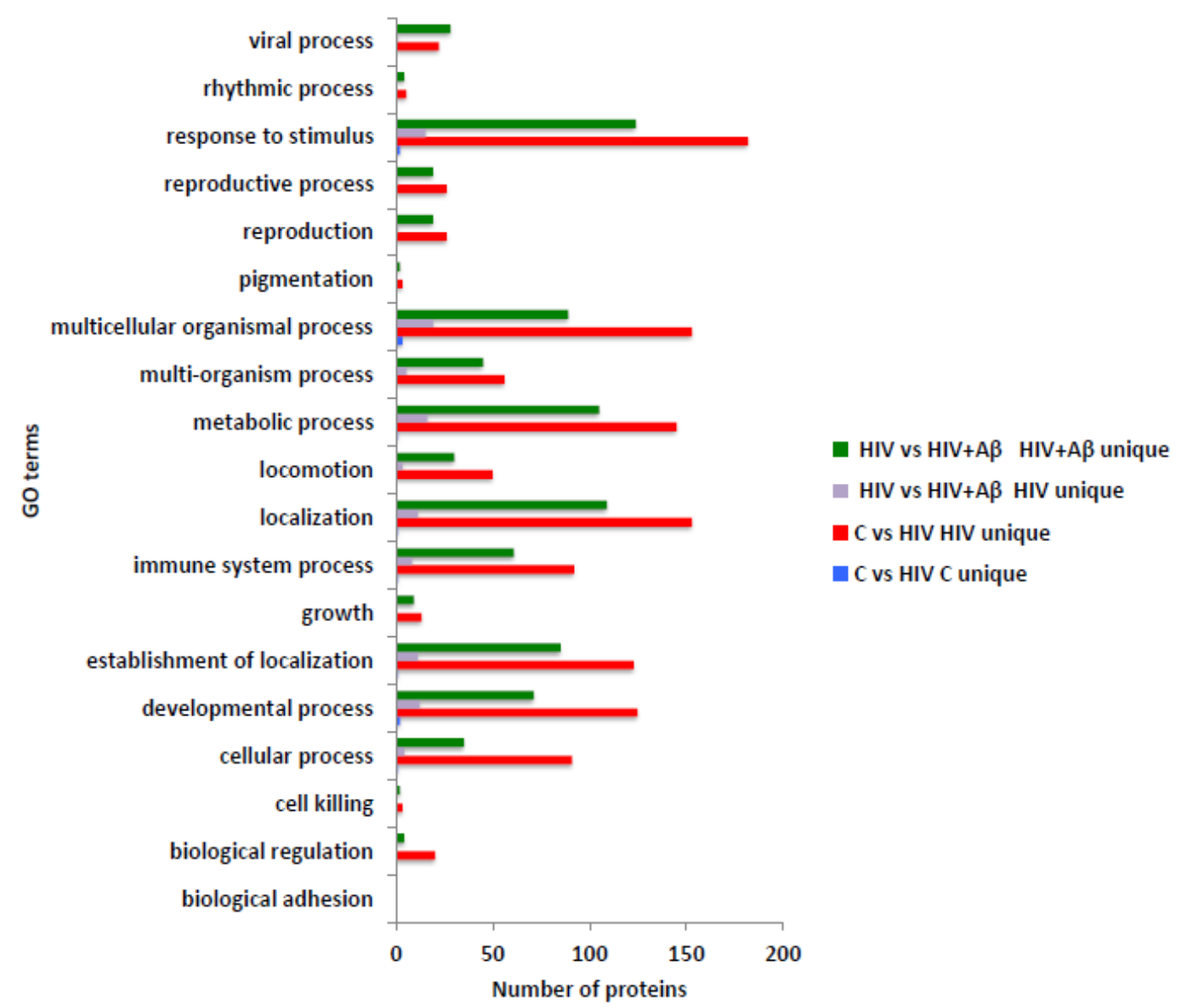

Figure 2. Enrichment for biological processes of the identified unique EV proteins. Scaffold software was used to enrich for the main biological processes for the identified unique EV proteins. The upper Venn diagrams show the compared groups with the number of their unique and shared proteins. The lower pie charts depict the enriched biological processes corresponding to the unique lists highlighted in yellow. The number of proteins in a particular biological process category is also provided. (A) Surface proteome, control vs. HIV. (B) Total proteome, control vs. HIV. (C) Surface proteome, HIV vs. HIV+ amyloid beta (A $\beta$ ). (D) Total proteome, HIV vs. HIV+A $\beta$. Combined graph for the biological processes in the EV unique surface (E) and total $(\mathbf{F})$ proteomes. The number of unique proteins corresponding to the main biological processes in the different comparisons is illustrated on the graph.

\subsection{Functional Enrichment of the Unique HBMEC-EV Proteins}

We next grouped these unique protein signatures into the biological process categories of the Scaffold software. Overall, 19 main categories were established, and the number of unique proteins mapping to these categories is illustrated in Figure 2, separately for the surface (A and C) and the total proteome (B and D). Note that individual proteins could map to more than one category; on the other hand, not all categories have been identified for all comparisons. This is consistent with the fact that selected group comparisons identified only a limited number of unique proteins that mapped to a limited number of categories. The number of unique proteins corresponding to the main biological process categories in the combined comparisons is illustrated on the bar graphs in Figure 2E for the surface proteome and Figure 2F for the total proteome. The majority of both surface and total unique proteins were mapped to "response to stimulus," "multicellular organismal process," "metabolic process," and "localization" categories. 
Next, we evaluated the unique proteins in the control vs. HIV and in the HIV vs. HIV+A $\beta$ comparisons using STRING for functional enrichment in the biological processes and the Kyoto Encyclopedia of Genes and Genomes (KEGG) Pathways. In addition, we enriched these analyses for cellular components and PMID publications.

The results of these analyses for the EV surface proteome unique proteins in the control group in the control vs. HIV comparison are listed in Table 4 and Supplementary Table S1A. In addition, Supplementary Table S1B lists the enrichment for cellular components. The observed gene count (Obs), background gene count (Bgr), false discovery rate (FDR), and matched proteins are also included in these tables. The three unique proteins identified when comparing the surface proteome in the HIV group to the control group are dynein heavy chain 8, axonemal (DNAH8), titin (TTN), and immunoglobulin heavy constant gamma 2 (IGHG2). According to the description in the STRING or GeneCards database, DNAH8 is a force-generating protein of the respiratory cilia and is also involved in sperm motility. In addition, DNAH8 is highly expressed in prostate cancer [21]. Titin appears to be a key component of the vertebrate striated muscles [22]. IGHG2 may take part in antigen binding and the regulation of actin dynamics. It was linked to severe respiratory syncytial virus infection [23]. Overall, very limited or no data were found for the different enrichment analyses in STRING regarding these three proteins.

Next, we analyzed the EV surface proteome unique lists for the HIV vs. HIV+A $\beta$ comparison in order to dissect the effect of exogenous EV-A $\beta$ cargo in the context of HIV. In this analysis, six unique proteins were identified in the HIV group, namely, TTN, ninein (NIN), DNAH8, adenylyl cyclase-associated protein 1 (CAP1), actin-related protein 2/3 complex subunit 4 (ARPC4), and IGHG2. For these unique proteins, all enriched biological processes are shown in Table 5. No KEGG pathways were enriched; however, several PMID publications were found by textmining (Table 5). Cellular localization of these enriched proteins to only a few categories was found, namely, "cytoskeletal part" (ARPC4, CAP1, DNAH8, NIN, TTN), "actin cytoskeleton" (ARPC4, CAP1, TTN), "supramolecular fiber" (DNAH8, NIN, TTN), "microtubule" (DNAH8, NIN), "ciliary part" (DNAH8, NIN), and "cytoplasmic region" (CAP1, DNAH8).

For the unique proteins in the HIV $+\mathrm{A} \beta$ group in this comparison, the enriched biological processes, KEGG pathways, and PMID publications are presented in Table 6 and Supplementary Table S2A. The enrichment for cellular components is included in Supplementary Table S2B.

Next, we analyzed the EV total proteome unique lists for the control vs. HIV comparison. For the unique proteins in the control group, no gene ontology (GO) terms were found for biological processes. Similarly, no KEGG Pathways were enriched, likely because only three unique proteins were identified in this group and comparison. The cellular localization of these proteins is presented in Supplementary Table S3. In addition, the first 10 PMID publications enriched are shown in Table 7. The total proteome revealed 259 unique proteins in the HIV group that mapped to a variety of GO terms for biological processes (Table 8 and Supplementary Table S4A). They were also enriched in several KEGG pathways (Table 8) and assigned to diverse cellular components, as listed in Supplementary Table S4B. Textmining resulted in an unbiased PubMed search with the 10 most significant publications listed in Table 8.

Finally, we analyzed the list of the unique proteins present in the total HBMEC-EV proteome in the HIV and HIV $+\mathrm{A} \beta$ groups. The unique proteins in the HIV group in this comparison mapped to only one GO term for biological processes, namely, "cell envelope organization," presented in Table 9. No KEGG pathways and no cellular components were enriched for this group. The first 10 textmined PMID citations are presented in Table 9. The unique proteins in the HIV+A $\beta$ group were enriched to several biological processes, KEGG pathways, and PMID publications (Table 10 and Supplementary Table S5A). Supplementary Table S5B lists the enrichments for the cellular component in this group.

\subsection{Analysis of Unique Protein Interactions}

We also explored in STRING whether these unique proteins have functional interactions among each other. The statistical background assumed for this enrichment analysis was the whole human 
genome. We filtered our search for established interactions only for the input proteins, for the highest confidence (over 0.900), and for a static map without the protein structures. In the obtained interaction maps, different nodes are connected with colored lines depending on the functional association type. The results imply that the identified proteins have more interactions among themselves than what would be expected for a random set of proteins of similar size, drawn from the genome. Such enrichments indicate that the proteins are, at least partially, biologically connected as a group and may contribute jointly to shared functions.

The interactions of the 112 unique surface proteins in the control group as compared to the HIV group are illustrated in Figure 3A. The HIV group in this comparison had only three unique surface proteins (DNAH8, TTN, and IGHG2). Being present on the EV surface, these proteins may be prone to interact with their potential functional partners beyond the EV surface. Therefore, we examined their possible interactions not only with each other but with other proteins as well. The STRING program identified predicted functional partners for DNAH8 and TTN, and the top five candidates that were predicted with the highest confidence, as well as their interacting networks, are illustrated in Figure 3B.

Next, we evaluated the unique surface protein list in the HIV vs. HIV+A $\beta$ group. No proteinprotein interactions were found for the six proteins uniquely expressed in the HIV group. By contrast, the $\mathrm{HIV}+\mathrm{A} \beta$ unique surface proteins had several complex interactions, as illustrated in Figure 3C.

Finally, we analyzed the interactions between the unique proteins present in the total HBMEC-EV proteome. No interactions were found in the control group as compared to the HIV group; however, the elaborate interaction map for the total unique proteins in the HIV group is presented in Figure 4A. For the HIV vs. HIV $+\mathrm{A} \beta$ comparison, the HIV group exhibited 28 unique proteins without any identified interactions. In contrast, the unique proteins in the HIV $+\mathrm{A} \beta$ group showed a complicated interaction network, as illustrated in Figure 4B.

A

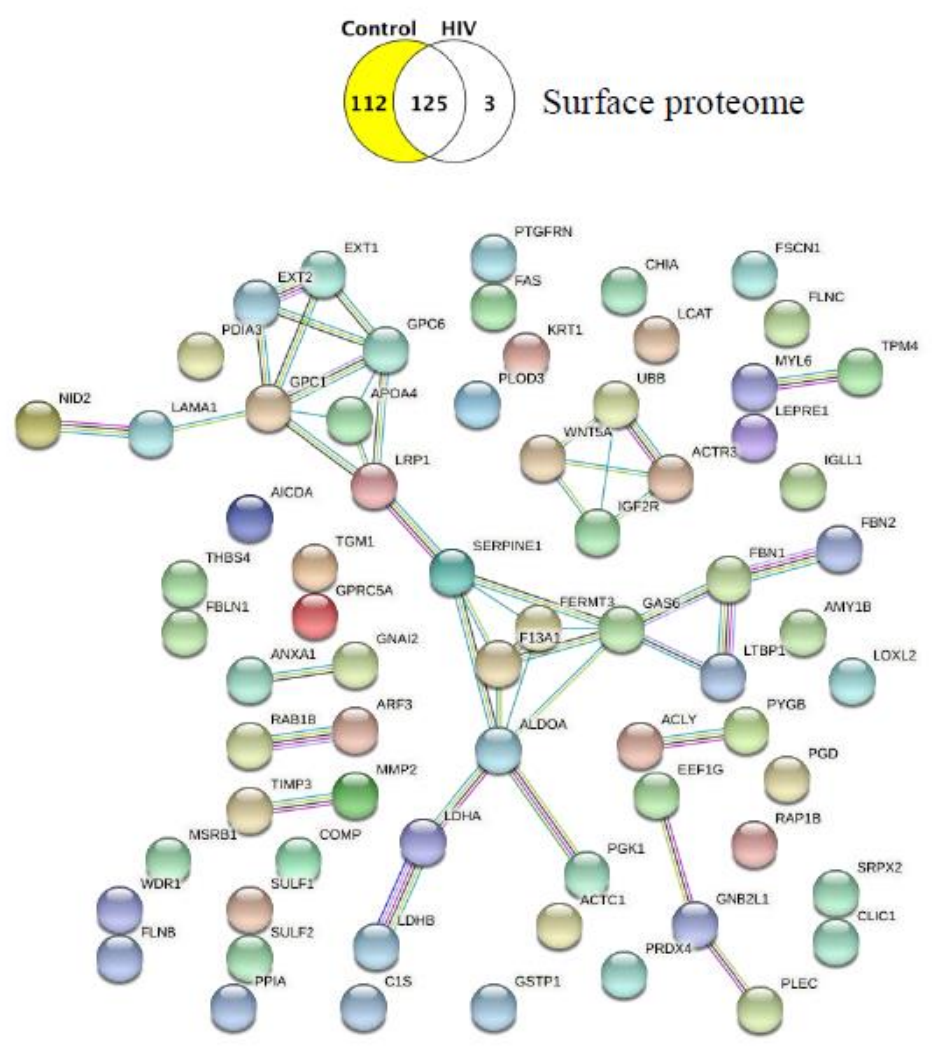

Figure 3. Cont. 


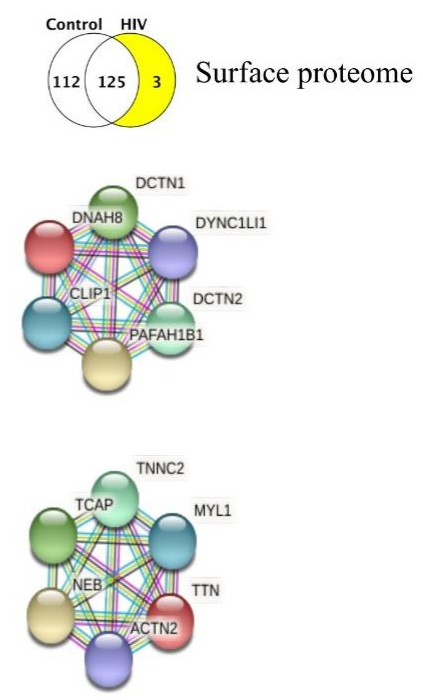

C

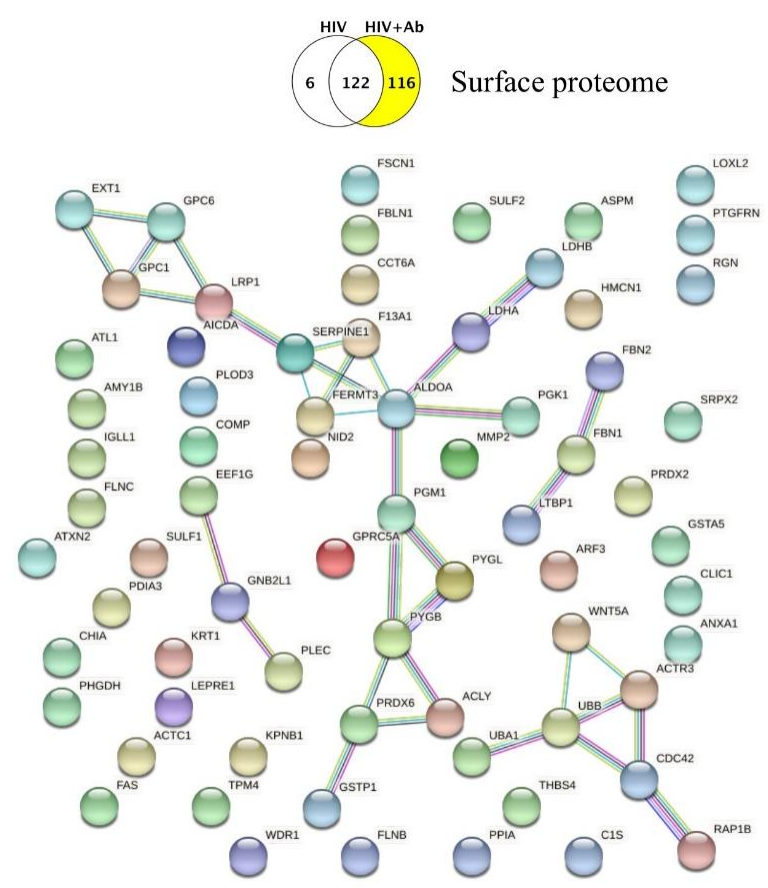

Figure 3. Protein-protein interactions between the identified unique proteins of the EV surface proteome. Venn diagrams illustrating the type of comparison and the number of identified unique proteins (highlighted). (A) Protein-protein interactions (PPI) (STRING) among the unique surface proteins in the control group. Only interactions with the highest confidence are shown with a minimum required interaction score of 0.900 (PPI enrichment p-value: $6.59 \times 10^{-7}$; the network has significantly more interactions than expected). Known interactions: From curated databases (turquoise), experimentally determined (pink); predicted interactions: Gene neighborhood (green), gene fusions (red), gene co-occurrence (blue); other interactions: Textmining (light green), co-expression (black), protein homology (purple). (B) No interactions with highest confidence were identified in STRING among the three unique proteins identified in the HIV group. Predicted functional partners of dynein heavy chain 8, axonemal (DNAH8) (upper map) and titin (TTN) (lower map). Only the first shell of five interactions with the highest confidence is shown. Color code of the interaction lines as described in (A). (C) Protein-protein interactions among the unique proteins in the HIV $+\mathrm{A} \beta$ group. Only interactions with the highest confidence are shown (PPI enrichment p-value: 0.00158; the network has significantly more interactions than expected). Color code of the interaction lines as described in (A). 
A

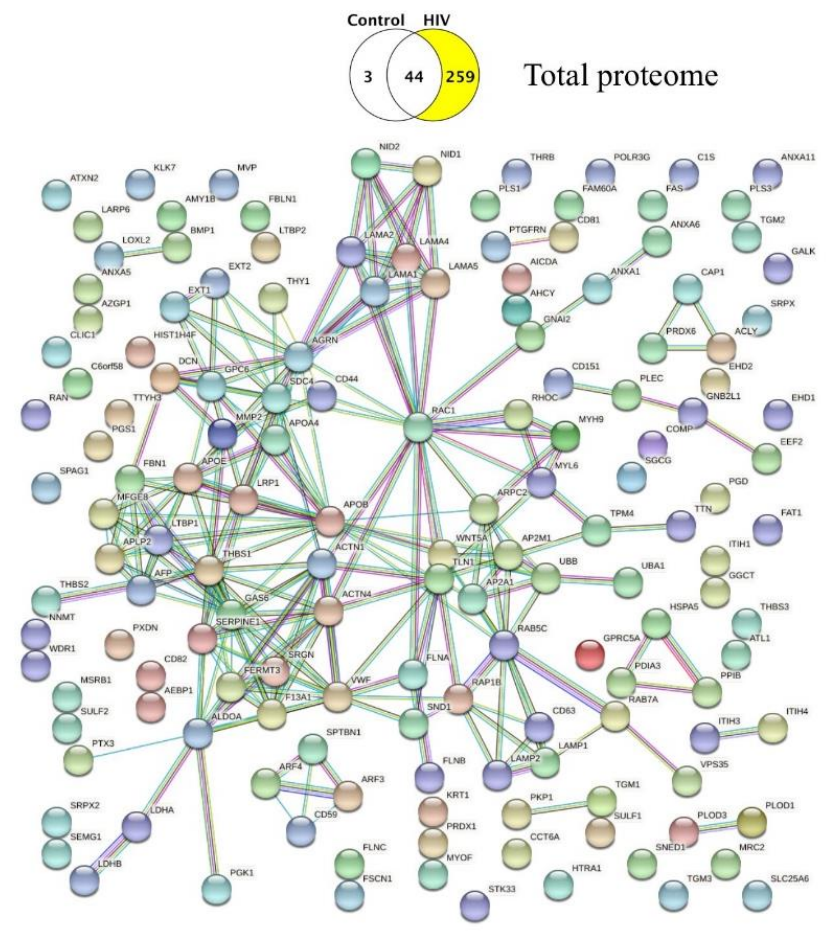

B

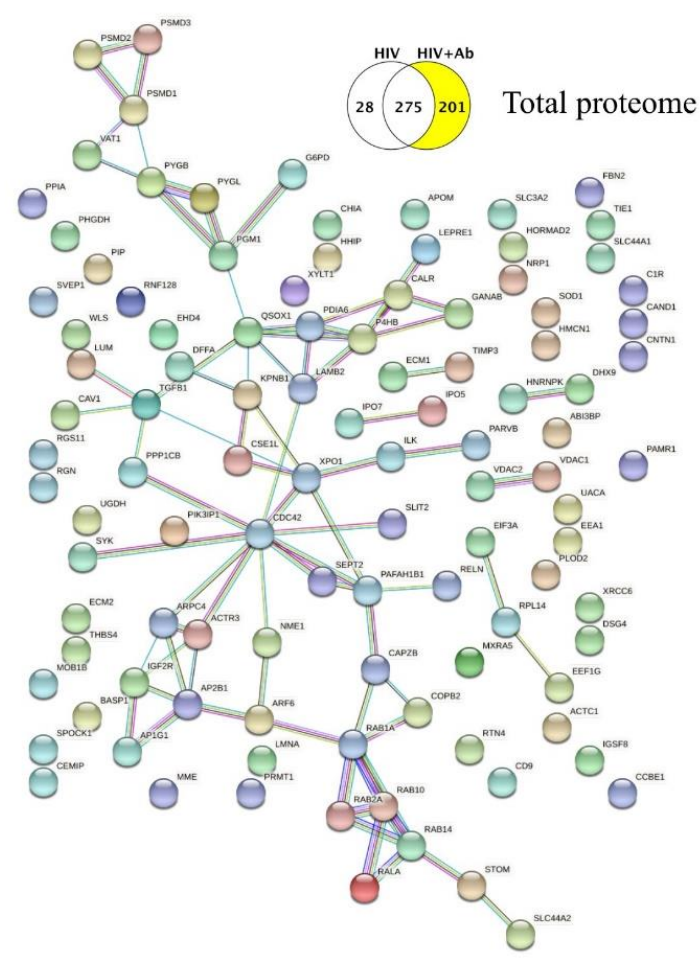

Figure 4. Protein-protein interactions in the identified unique proteins of the EV total proteome. Venn diagrams illustrating the type of comparison and the number of identified unique proteins (highlighted). (A) Protein-protein interactions among the unique proteins in the HIV group. Only interactions with the highest confidence are shown (PPI enrichment p-value: $1.0 \times 10^{-16}$; the network has significantly more interactions than expected). (B) Protein-protein interactions among the unique proteins in the $\mathrm{HIV}+\mathrm{A} \beta$ group. Only interactions with the highest confidence are shown (PPI enrichment $\mathrm{p}$-value: $1.45 \times 10^{-7}$; the network has significantly more interactions than expected). Color code of the interaction lines as described in Figure 3A. 


\section{Discussion}

In the current study, we evaluated HBMEC-EV surface and total proteome changes evoked by HIV- 1 alone and together with A $\beta$. We limited our analyses to the unique lists of proteins identified in the treatment groups; thus, we did not include the shared protein lists and the complex changes in the up- and down-regulated proteins. In addition, we specifically focused on the unique proteins in the control vs. HIV and in the HIV vs. HIV $+\mathrm{A} \beta$ group comparisons. The identified proteins were mapped to different gene ontology (GO) terms for biological processes, KEGG pathways, and Cell Components. We also explored the protein-protein interactions among the identified unique proteins.

Overall, the surface proteome control vs. HIV comparison indicated that the functions of the identified unique proteins ranged from diverse biological processes in the control (mainly "extracellular matrix organization," "metabolic processes," "vesicle-mediated transport," "exocytosis") and KEGG pathways (mainly "proteoglycans in cancer," "focal adhesion," "carbohydrate and cholesterol metabolism," "HIF-1 signaling pathway") to few or no distinct biological processes in the HIV group (Figure 2A and Table 4). The latter phenomenon was likely due to the limited number of proteins (namely, DNAH8, TTN, IGHG2) that were unique in the HIV-1 group when compared to the HBMEC-EV surface proteome of the controls. Nevertheless, we found several potential functional partners for DNAH8, such as platelet-activating factor acetylhydrolase IB subunit alpha (PAFAH1B1), dynactin subunit 1 (DCTN1), dynactin subunit 2 (DCTN2), CAP-Gly domain-containing linker protein 1 (CLIP1), and cytoplasmic dynein 1 light intermediate chain 1 (DYNC1LI1). Similarly, we identified several predicted functional partners for TTN, namely, nebulin (NEB), telethonin (TCAP), troponin C, skeletal muscle (TNNC2), myosin light chain 1/3, skeletal muscle isoform (MYL1), and alpha-actinin-2 (ACTN2) (Figure 3B). Thus, these few unique surface EV proteins in the HIV group may engage primarily with proteins of actin cytoskeleton/microtubule remodeling and vesicle-mediated transport.

The control EV proteome exhibited more than a hundred unique proteins; thus, it appears that after HIV-1 exposure of the parent cells, the EV surface proteome almost completely "blended" into the control proteome. This relative lack of surface HBMEC-EV protein signature in the HIV group is particularly striking in light of our previous findings where the exposure of HBMEC to HIV results in increased EV shedding [18] and the fact that EVs are involved in spreading HIV infection to the neighboring cells. However, it is possible that the localization of some proteins could alter from the EV surface to the vesicle lumen, resulting in a highly enriched total but not surface proteome. Indeed, comparison of the total proteome revealed a highly diverse number of 259 unique proteins in the HIV group as compared to the control that mapped to a variety of biological processes and KEGG pathways. The most prominent enrichment among the biological processes category was "vesicle-mediated transport," followed by "extracellular structure organization." In addition, mapping these unique proteins to "exocytosis" and "secretion by cell" categories points to processes that may be involved in EV release and EV transport (Figure 2B and Table 8). Likewise, the KEGG pathways were also diverse, from "focal adhesion" and "endothelial cell medium (ECM)-receptor interaction" to "proteoglycans in cancer," different infections, "endocytosis," "cholesterol metabolism," and "glycolysis/gluconeogenesis" (Table 8). Thus, the total EV proteome in the HIV group, with a large number of unique proteins, may suggest that the rich, unique cargo is somewhat "hidden" within the EVs with a surface proteome that was barely altered. This notion is supported by the observations that the HIV group in the HIV versus $\mathrm{HIV}+\mathrm{A} \beta$ group surface proteome comparison also exhibited only six unique proteins (Figure 2C). On the other hand, the relative lack of unique EV surface protein signatures may facilitate EV internalization and, thus, HIV transmission to other cells.

In addition to the effects of HIV-1, we explored the impact of $A \beta$ on the HBMEC-EV proteome in the context of HIV-1. It was reported that increased brain $A \beta$ induced profound proteome remodeling in multiple cell types, altering brain molecular pathways in an Alzheimer's disease (AD) mouse model [24]. Another brain proteomic study using a different AD mouse model with amyloid and neurofibrillary tangle pathologies indicated age-dependent immune responses and synaptic dysfunctions. It was proposed that these changes were evoked by the advancing $\mathrm{A} \beta$ pathology in the 
brain [25], further demonstrating the importance of proteomic analyses in studies on the mechanisms of amyloid pathology.

Comparison of surface proteomes of EVs derived from HBMEC exposed to HIV alone vs. HIV+A $\beta$ revealed profound changes, as demonstrated by 116 unique proteins in the HIV+A $\beta$ group (Figure $2 \mathrm{C}$ ). $A \beta$, acting on a HIV background, appeared to shift biological processes from mainly actin cytoskeleton organization (Table 5) to immune responses, extracellular matrix organization, and carbohydrate metabolic processes. In addition, enrichment of the "vesicle-mediated transport" and "exocytosis" also pointed to processes involved in EV release and EV transport (Figure 2C and Table 6). The KEGG pathways changed from a "blended" profile in the HIV group to a very diverse profile in the HIV+A $\beta$ group, pointing mainly to the carbohydrate metabolic processes, "focal adhesion," different infections, and signaling pathways as demonstrated by HIF-1, MAPK, and AGE-RAGE enrichment (Table 6). Regarding these signaling pathways, we have shown before the involvement of the RAGE pathway in the HIV-induced $A \beta$ accumulation in HBMEC [26].

The HIV vs. HIV $+\mathrm{A} \beta$ comparison for the total proteome indicated substantial remodeling in the $\mathrm{HIV}+\mathrm{A} \beta$ with 201 unique proteins as compared to 28 of such proteins in the HIV group. Consistent with $\mathrm{HIV}+\mathrm{A} \beta$-mediated EV release [18], the biological processes changed from "cell envelope organization" (Table 9) to mainly "vesicle-mediated transport," "exocytosis," and immune responses (Figure 2D and Table 10). The KEGG pathways also shifted to a diverse profile. "Endocytosis" was the most significant, followed by "focal adhesion" and "bacterial invasion of epithelial cells." Several proteins were part of the carbohydrate metabolic pathways, such as the "pentose phosphate pathway," "starch and sucrose metabolism," and "proteoglycans in cancer" (Table 10).

Surprisingly, surface and total proteome analysis across different groups did not find any $A \beta$ species in EVs, not even in samples that were isolated from $A \beta$-exposed HBMEC. This lack of $A \beta$ identification could be related to technical issues, such as aggregation of $A \beta$, its insolubility, and possibly indigestibility by trypsin. The tryptic peptide used to quantify $\beta$-amyloid, LVFFAEDVGSNK, corresponding to amino acids 688-699, maps to all species of A $\beta$ and full-length APP [27] and has been identified in the human CSF proteome [28]. In our study, no peptides mapping to the A $\beta$-generating region of APP were identified, even though APP was identified on the surface proteome. Similar obstacles were described in another proteomic study, in which $A \beta$ was not identified in human AD brains. However, $A \beta$ was detected by dot blot and ELISA from the same samples [29], supporting the notion that the lack of $A \beta$ detection in the proteome was likely due to technical limitations.

Our previous studies demonstrated that treatment of HBMEC with A $\beta$ could enrich EVs with this peptide, which can then be carried and delivered to different cells of the neurovascular unit $[18,30]$. In support of these findings, literature reports described $A \beta$ as being present on the EV surface. For example, neuron-derived EVs accelerated $A \beta$ fibril formation from monomeric $A \beta$, and this process was inhibited by cleavage of glycosphingolipid (GSL) glycans by endoglycoceramidase (EGCase) [31]. The same group also demonstrated that EV GSL-glycans were critical for A $\beta$ binding in vitro and in vivo [15]. GSLs are found mainly in lipid rafts in the outer layer plasma membrane with their glycans facing outside; however, they are more abundant in EVs than in the parent cells [15]. Besides GSL, EVs were shown to bind $\mathrm{A} \beta$ through the prion protein $(\mathrm{PrP})[14]$, a glycosylphosphatidylinositol-anchored protein in the outer leaflet of the neuron and neuron-derived EV membrane [32].

Some of the unique proteins identified in our HBMEC-derived EVs exhibit a substantial overlap with proteins detected by label-free proteomics in A $\beta$-enriched extracts from human AD brains [29], suggesting the relevance of EV proteins to A $\beta$ pathology. The examples include ANXA5, FGB, LAMA5, and VIM found both in the total proteome of EVs in the HIV group and in $A \beta$-enriched extracts from human AD brains [29]. In addition, specific types of tubulins, such as TUBA1B and TUBB4B, were present, although they did not change in AD brains. Among the unique proteins in the HIV+A $\beta$ group's total proteome, FGG and HIST1H2BK, as well as tubulins TUBB and TUBB2A, were also enriched in extracts from AD brains [29]. In addition, HIST1H2BK has been one of the unique proteins in the EV total proteome from the A $\beta$ group. In contrast, RNF213 was not identified in any of our 
EV samples, although it was unique to the AD brain samples and also found within the amyloid plaques [29]. One explanation for this phenomenon could be that RNF213 in the AD brain might not originate from brain endothelial cells.

Analysis for predicted significant functional interactions among the unique proteins produced several elaborate interaction maps (Figures 3 and 4). It is striking to notice that several proteins on these maps act like "hubs" or centers by having a substantial number of connections to other proteins. Such "hubs" for the surface proteomes were SERPINE1 (PAI-1), GPC1, FERMT3 (Figure 3A), and ALDOA (Figure 3C). The most complex functional interaction maps were obtained for the total proteomes due to the high number of unique proteins. The identified "hubs" were RAC1, GAS6, SERPINE1, AGRN, APOB, and RAB5C (Figure 4A), as well as CDC42 and RAB1A (Figure 4B). Among these proteins, endothelial AGRN (agrin) was shown to be implicated in the brain A $\beta$ pathology. For example, deletion of the Agrn gene from endothelial cells resulted in significantly increased A $\beta$ levels in the mouse brain; however, overexpression of Agrn restored brain A $\beta$ levels [33]. SERPINE1 (PAI-1) and GPC1 (glypican-1) may be additional important players in the A $\beta$ pathology $[34,35]$. Indeed, GPC1, a heparan sulfate proteoglycan, localized mainly in detergent-insoluble, GSL-rich membrane domains, was shown to bind fibrillar $A \beta$ in the human brain [36], further suggesting that protein "hubs" identified in the present study may be involved in EV-mediated A $\beta$ pathology.

In summary, our results provide information, with an unprecedented resolution, on the brain endothelial surface and total EV proteome changes after HIV and A $\beta$ exposure of the parent cells. The analyses identified protein-protein interaction networks, biological processes, pathways, and cellular localization. Overall, the obtained results factor for a better understanding of HBMEC-EV protein landscape changes induced by HIV and $A \beta$ and their contribution to the HIV-associated A $\beta$ pathology in the brain.

\section{Materials and Methods}

\subsection{Cell Cultures}

Primary human brain microvascular endothelial cells (HBMEC) used in the study were purchased from ScienCell Research laboratories (Carlsbad, CA, USA). HBMEC were isolated from human brain and cryopreserved at passage one. HBMEC were characterized by immunofluorescence with antibodies specific to vWF/Factor VIII and CD31 (PECAM). Cells were cultured on bovine plasma fibronectin (ScienCell)-coated dishes in endothelial cell medium (ECM). Specifically, $500 \mathrm{~mL}$ of basal ECM medium was supplemented with $25 \mathrm{~mL}$ of exosome-depleted fetal bovine serum (Exo-FBS; System Biosciences, Mountain View, CA, USA), $5 \mathrm{~mL}$ of endothelial cell growth supplement (ECGS, ScienCell), and $5 \mathrm{~mL}$ of penicillin/streptomycin solution (P/S, ScienCell). We initiated two separate cultures on $100 \mathrm{~mm}$ cell culture dishes to reduce the number of passages and subcultured the cells twice at the 1:4 ratio. This resulted in 32 confluent cultures, with the average cell number at the end of experiment of $9.065 \times 10^{7}$ cells/dish. Sixteen confluent cultures were used for EV surface proteomics, and 16 for EV total proteomics. The treatment groups were: 1) Control exposed to vehicle, 2) A $\beta$ alone, 3) HIV alone, 4) HIV plus $A \beta$, with four samples/group.

\subsection{HIV Infection and $A \beta$ Treatment}

HIV-1 stock was generated using human embryonic kidney (HEK) 293T cells (ATCC, Manassas, VA, USA) transfected with pYK-JRCSF plasmid containing full-length proviral DNA. Throughout the study, HBMEC were exposed to HIV particles at the p24 level of $30 \mathrm{ng} / \mathrm{mL}$ as previously reported [37]. Treatment was terminated by removing the cell culture media for EV isolation.

A $\beta$ (1-40) was purchased from Anaspec (San Jose, CA, USA) and dissolved in PBS. Freshly solubilized $A \beta$ solutions without pre-aggregation were used for experiments as such a form of $A \beta$ was demonstrated to induce proinflammatory reactions in isolated rat brain microvessels [38]. Cells were treated with $\mathrm{A} \beta(1-40)$ at the concentration of $100 \mathrm{nM}$ for $48 \mathrm{~h}$ in complete medium. Although uptake 
of $A \beta$ by the BBB occurs rapidly [39], we terminated the treatment at $48 \mathrm{~h}$ to allow more EV to be secreted into the culture medium. Confluent HBMEC were exposed to HIV-1 or/and A $\beta$ (1-40) for $48 \mathrm{~h}$.

\subsection{EV Isolation}

EV isolation was performed using ExoQuick-TC precipitation solution (System Biosciences) from conditioned culture media according to the manufacturer's specifications. Briefly, $10 \mathrm{~mL}$ culture media from confluent HBMEC cultures was centrifuged at $3000 \mathrm{~g}$ for $15 \mathrm{~min}$ to remove cells and debris, and then mixed thoroughly with $2 \mathrm{~mL}$ of Exo-Quick precipitation solution and incubated overnight at $4{ }^{\circ} \mathrm{C}$. The next day, samples were centrifuged at $1500 \mathrm{~g}$ for $30 \mathrm{~min}$, and the supernatants were removed and centrifuged again at $1500 \mathrm{~g}$ for $5 \mathrm{~min}$. The EV pellets were stored at $-80^{\circ} \mathrm{C}$ and used for proteomics analysis. Separate EV samples were prepared for EV surface and total proteomics.

\subsection{Proteomics}

Sample Preparation. Each sample was processed by SDS-PAGE using a 10\% Bis Tris NuPage mini-gel (Invitrogen, Waltham, MA, USA) in the MES buffer system. The migration windows $(1 \mathrm{~cm}$ lane) were excised and processed by in-gel digestion with trypsin using a ProGest robot (DigiLab) with the following protocol: The samples were washed with $25 \mathrm{mM}$ ammonium bicarbonate followed by acetonitrile, reduced with $10 \mathrm{mM}$ dithiothreitol at $60^{\circ} \mathrm{C}$, followed by alkylation with $50 \mathrm{mM}$ iodoacetamide at room temperature, digested with trypsin (Promega, Madison, WI, USA) at $37^{\circ} \mathrm{C}$ for $4 \mathrm{~h}$, and quenched with formic acid. The supernatants were then analyzed directly without further processing.

Mass Spectrometry. Half of each digested sample was analyzed by nano LC-MS/MS with a Waters NanoAcquity HPLC system interfaced to a ThermoFisher Q Exactive. Peptides were loaded on a trapping column and eluted over a $75 \mu \mathrm{m}$ analytical column at $350 \mathrm{~nL} / \mathrm{min}$; both columns were packed with Luna C18 resin (Phenomenex, Torrance, CA, USA). The mass spectrometer was operated in data-dependent mode, with the Orbitrap operating at 70,000 FWHM and 17,500 FWHM for MS and MS/MS respectively. The fifteen most abundant ions were selected for MS/MS.

Data Processing. Data were searched using Mascot (Matrix Science, London, UK; version 2.6.0) with the following parameters: Enzyme: Trypsin/P; Databases: SwissProt Human (concatenated forward and reverse plus common contaminants); fixed modifications: Carbamidomethyl (C); variable modifications: Acetyl (N-term), deamidation $(\mathrm{N}, \mathrm{Q})$, oxidation $(\mathrm{M})$, Pyro-Glu (N-term $\mathrm{Q})$; mass values: Monoisotopic; peptide mass tolerance: $10 \mathrm{ppm}$; fragment mass tolerance: $0.02 \mathrm{Da}$; max missed cleavages: 2. Mascot DAT files were parsed into Scaffold (Proteome Software, version Scaffold 4.8.7, Proteome Software Inc., Portland, OR, USA) for validation, filtering, and to create a non-redundant list per sample. Data were filtered using a 1\% protein and peptide FDR and required at least two unique peptides per protein. Protein probabilities were assigned by the Protein Prophet algorithm [40]. Proteins that contained similar peptides and could not be differentiated based on MS/MS analysis alone were grouped to satisfy the principles of parsimony. Proteins were annotated with GO terms from NCBI (downloaded on Sep 6, 2018) [41]. The normalized spectral abundance factor (NSAF) calculation contains the conversion to the spectral abundance factor (SAF) and subsequent normalized spectral abundance factor (NSAF). This was based on the equation: NSAF $=(\mathrm{SpC} / \mathrm{MW}) / \Sigma(\mathrm{SpC} / \mathrm{MW}) \mathrm{N}$, where $\mathrm{SpC}=$ spectral counts, $\mathrm{MW}=$ protein molecular weight in $\mathrm{kDa}$, and $\mathrm{N}=$ total number of proteins. NSAF values can be used to approximate the relative abundance of proteins within a given sample and the relative abundance of a given protein between samples. The different treatment groups were compared using the $t$-test, and $p<0.05$ was considered significant.

\subsection{ExoCarta Database Search and Functional Enrichment Analysis}

The list of the top 100 proteins most often identified in EVs was composed based on the ExoCarta EV proteomics database from different human cell types [19]. Enrichment in molecular functions of the identified EV proteins was analyzed using the Scaffold Proteome Software and STRING [42]. 
A gene ontology analysis study was carried out with the proteomic profiles obtained to identify overrepresentation profiles. Gene ontology was investigated at the levels of the biological process, KEGG pathways, and cell component. Textmining in STRING provided the most relevant publications for a particular enrichment. Kyoto Encyclopedia of Genes and Genomes (KEGG) established pathway maps representing molecular interactions, reactions, and relation networks for Metabolism, Genetic Information Processing, Environmental Information Processing, Cellular Processes, Organismal Systems, Human Diseases and Drug Development. KEGG PATHWAY is the reference database for pathway mapping in KEGG Mapper.

Table 1. List of the top 100 ExoCarta proteins present in the brain endothelial extracellular vesicle (EV) surface (S) and total (T) proteome. Bold, top 100 ExoCarta proteins present in S or T; bold and red, proteins present in both $S$ and $T$.

\begin{tabular}{|c|c|c|c|}
\hline & Gene Symbol & Detected in S & Detected in $\mathrm{T}$ \\
\hline 1 & CD9 & - & + \\
\hline 2 & HSPA8 & + & + \\
\hline 3 & PDCD6IP & + & + \\
\hline 4 & GAPDH & + & + \\
\hline 5 & АСТВ & + & + \\
\hline 6 & ANXA2 & + & + \\
\hline 7 & CD63 & - & + \\
\hline 8 & SDCBP & + & + \\
\hline 9 & ENO1 & + & + \\
\hline 10 & HSP90AA1 & + & + \\
\hline 11 & TSG101 & - & + \\
\hline 12 & PKM & + & + \\
\hline 13 & LDHA & + & + \\
\hline 14 & EEF1A1 & + & + \\
\hline 15 & YWHAZ & + & + \\
\hline 16 & PGK1 & + & + \\
\hline 17 & EEF2 & + & + \\
\hline 18 & ALDOA & + & + \\
\hline 19 & HSP90AB1 & + & + \\
\hline 20 & ANXA5 & + & + \\
\hline 21 & FASN & + & + \\
\hline 22 & YWHAE & + & + \\
\hline 23 & CLTC & + & + \\
\hline 24 & CD81 & - & + \\
\hline 25 & ALB & + & + \\
\hline 26 & $\mathrm{VCP}$ & + & + \\
\hline 27 & TPI1 & + & + \\
\hline 28 & PPIA & + & + \\
\hline 29 & MSN & + & + \\
\hline 30 & CFL1 & + & + \\
\hline 31 & PRDX1 & + & + \\
\hline 32 & PFN1 & + & + \\
\hline 33 & RAP1B & + & + \\
\hline 34 & ITGB1 & + & + \\
\hline 35 & HSPA5 & + & + \\
\hline 36 & SLC3A2 & - & + \\
\hline 37 & HIST1H4A & + & + \\
\hline 38 & GNB2 & - & - \\
\hline 39 & ATP1A1 & - & + \\
\hline 40 & YWHAQ & + & + \\
\hline 41 & FLOT1 & - & - \\
\hline 42 & FLNA & + & + \\
\hline 43 & CLIC1 & + & + \\
\hline
\end{tabular}


Table 1. Cont.

\begin{tabular}{|c|c|c|c|}
\hline & Gene Symbol & Detected in S & Detected in $\mathrm{T}$ \\
\hline 44 & CDC42 & + & + \\
\hline 45 & ССТ2 & + & + \\
\hline 46 & A2M & + & + \\
\hline 47 & YWHAG & + & + \\
\hline 48 & TUBA1B & + & + \\
\hline 49 & RAC1 & - & + \\
\hline 50 & LGALS3BP & + & + \\
\hline 51 & HSPA1A & + & + \\
\hline 52 & GNAI2 & + & + \\
\hline 53 & ANXA1 & + & + \\
\hline 54 & RHOA & - & - \\
\hline 55 & MFGE8 & - & + \\
\hline 56 & PRDX2 & + & - \\
\hline 57 & GDI2 & + & + \\
\hline 58 & EHD4 & - & + \\
\hline 59 & ACTN4 & + & + \\
\hline 60 & YWHAB & - & - \\
\hline 61 & RAB7A & - & + \\
\hline 62 & LDHB & + & + \\
\hline 63 & GNAS & - & - \\
\hline 64 & TFRC & - & - \\
\hline 65 & RAB5C & - & + \\
\hline 66 & ARF1 & - & - \\
\hline 67 & ANXA6 & + & + \\
\hline 68 & ANXA11 & - & + \\
\hline 69 & ACTG1 & - & - \\
\hline 70 & KPNB1 & + & + \\
\hline 71 & EZR & - & + \\
\hline 72 & ANXA4 & - & - \\
\hline 73 & ACLY & + & + \\
\hline 74 & TUBA1C & - & - \\
\hline 75 & RAB14 & - & + \\
\hline 76 & HIST2H4A & - & - \\
\hline 77 & GNB1 & + & + \\
\hline 78 & UBA1 & + & + \\
\hline 79 & THBS1 & + & + \\
\hline 80 & RAN & + & + \\
\hline 81 & RAB5A & - & - \\
\hline 82 & PTGFRN & + & + \\
\hline 83 & ССТ5 & + & + \\
\hline 84 & ССТ3 & - & + \\
\hline 85 & BSG & - & + \\
\hline 86 & AHCY & + & + \\
\hline 87 & RAB5B & - & - \\
\hline 88 & RAB1A & - & + \\
\hline 89 & LAMP2 & - & + \\
\hline 90 & ITGA6 & - & - \\
\hline 91 & HIST1H4B & - & - \\
\hline 92 & GSN & + & + \\
\hline 93 & FN1 & + & + \\
\hline 94 & YWHAH & - & + \\
\hline 95 & TUBA1A & + & - \\
\hline 96 & TKT & - & - \\
\hline 97 & TCP1 & + & + \\
\hline 98 & STOM & - & + \\
\hline 99 & SLC16A1 & - & - \\
\hline 100 & RAB8A & - & - \\
\hline
\end{tabular}


Table 2. List of the unique proteins in the EV surface proteome.

\begin{tabular}{|c|c|c|c|c|c|c|c|}
\hline \multicolumn{4}{|c|}{ Control vs. HIV } & \multicolumn{4}{|c|}{ HIV vs. $H I V+A \beta$} \\
\hline \multicolumn{3}{|c|}{ Control Unique } & \multirow[t]{2}{*}{$\begin{array}{c}\text { HIV } \\
\text { Unique }\end{array}$} & \multirow[t]{2}{*}{$\begin{array}{c}\text { HIV } \\
\text { Unique }\end{array}$} & \multicolumn{3}{|c|}{$\mathrm{HIV}+\mathrm{A} \beta$ Unique } \\
\hline $1433 \mathrm{E}$ & GPC6 & TGM1 & & & $1433 \mathrm{E}$ & GPC1 & TCPA \\
\hline $1433 G$ & GSTP1 & TIG1 & & & $1433 G$ & GPC6 & ТСРВ \\
\hline $1433 \mathrm{~T}$ & IGL1 & TIMP3 & & & 1A34 & GSTA5 & ТСРЕ \\
\hline 1A34 & ITA3 & TPM4 & & & $1 \mathrm{~B} 15$ & GSTP1 & ТСРH \\
\hline 5NTD & ITAV & TRFE & & & 5NTD & HMCN1 & TCPZ \\
\hline 6PGD & ITB1 & TSP4 & & & ACLY & IGL1 & TIG1 \\
\hline ACLY & K2C6B & UBB & & & ACTC & IMB1 & TPM4 \\
\hline ACTC & LAMA1 & UGPA & & & ADA10 & ITA3 & TRFE \\
\hline ALDOA & LCAT & URP2 & & & AL9A1 & ITA5 & TSP4 \\
\hline AMPN & LDHA & VINC & & & ALDOA & ITAV & UBA1 \\
\hline AMY1 & LDHB & WDR1 & & & AMY1 & ITB1 & UBB \\
\hline ANXA1 & LOXL2 & WNT5A & & & ANXA1 & LDHA & UGPA \\
\hline APOA4 & LRC17 & & & & ARF3 & LDHB & URP2 \\
\hline ARF3 & LRP1 & & & & ARP2 & LOXL2 & VINC \\
\hline ARGI1 & LTBP1 & & & & ARP3 & LRC17 & WDR1 \\
\hline ARP2 & MIME & & & & ASPM & LRP1 & WNT5A \\
\hline ARP3 & MMP2 & & & & ATL1 & LTBP1 & \\
\hline ATS13 & MPRI & & & & ATX2 & MIME & \\
\hline C1S & MYL6 & & & & B4GA1 & MMP2 & \\
\hline CASPE & NID2 & & & & C1S & NID2 & \\
\hline CCD80 & $\mathrm{P} 3 \mathrm{H} 1$ & & & & CAZA1 & $\mathrm{P} 3 \mathrm{H} 1$ & \\
\hline CFAH & PAI1 & & & & CCD80 & PAI1 & \\
\hline CHIA & PCOC1 & & & TITIN & CDC42 & PDC6I & \\
\hline CLIC1 & PDC6I & & TITIN & NIN & CHIA & PDIA3 & \\
\hline $\mathrm{CO} 4 \mathrm{~A} 2$ & PDIA3 & & DYH8 & DYH8 & CHSS2 & PGK1 & \\
\hline CO5A2 & PGK1 & & IGHG2 & CAP1 & CISY & PGM1 & \\
\hline CO7 & PLEC & & & ARPC4 & CLIC1 & PLEC & \\
\hline CO7A1 & PLOD3 & & & IGHG2 & CLUS & PLOD3 & \\
\hline COBA1 & PPIA & & & & CO4A2 & PPIA & \\
\hline COF1 & PRDX4 & & & & CO5A2 & PRDX2 & \\
\hline COFA1 & PYGB & & & & CO7A1 & PRDX6 & \\
\hline COMP & RAB1B & & & & COBA1 & PUR6 & \\
\hline EF1G & RACK1 & & & & COF1 & PYGB & \\
\hline ENOB & RAP1B & & & & COFA1 & PYGL & \\
\hline EXT1 & RLA0 & & & & COMP & RACK1 & \\
\hline EXT2 & RS16 & & & & EF1G & RAP1B & \\
\hline F13A & S10A9 & & & & EXT1 & RGN & \\
\hline FA11 & SDCB1 & & & & F13A & RIMB1 & \\
\hline FAS & SEPR & & & & FA11 & RL12 & \\
\hline FBLN1 & SPB12 & & & & FAS & S10A9 & \\
\hline FBN1 & SPR1B & & & & FBLN1 & SDCB1 & \\
\hline FBN2 & SPR2E & & & & FBN1 & SERA & \\
\hline FLNB & SRCRL & & & & FBN2 & SERPH & \\
\hline FLNC & SRPX2 & & & & FLNB & SPR2E & \\
\hline FPRP & SULF1 & & & & FLNC & SRCRL & \\
\hline FRIH & SULF2 & & & & FPRP & SRPX2 & \\
\hline FSCN1 & SYTC & & & & FRIH & SULF1 & \\
\hline GAS6 & TAGL2 & & & & FRIL & SULF2 & \\
\hline GNAI2 & TBA1A & & & & FSCN1 & SYTC & \\
\hline GPC1 & TCPD & & & & GDIB & TAGL2 & \\
\hline
\end{tabular}


Table 3. List of the unique proteins in the EV total proteome.

\begin{tabular}{|c|c|c|c|c|c|c|}
\hline \multicolumn{7}{|c|}{ Control vs. HIV } \\
\hline \multirow[t]{2}{*}{ Control Unique } & \multicolumn{6}{|c|}{ HIV Unique } \\
\hline & $1433 \mathrm{~T}$ & CD81 & GDIB & MVP & S10AB & URP2 \\
\hline & $1433 Z$ & CD82 & GELS & MYH9 & SAHH & VIME \\
\hline & $1 \mathrm{~A} 24$ & CLH1 & GGCT & MYL6 & SCRB2 & VINC \\
\hline & 5NTD & CLIC1 & GNAI2 & MYOF & SDC4 & VPS35 \\
\hline & 6PGD & $\mathrm{CO} 1 \mathrm{~A} 2$ & GPC6 & NID1 & SDCB1 & VTNC \\
\hline & A4 & CO3A1 & GRP78 & NID2 & SEPR & VWF \\
\hline & ACLY & CO4A1 & GSLG1 & NNMT & SERPH & WDR1 \\
\hline & ACTN1 & $\mathrm{CO} 4 \mathrm{~A} 2$ & GTR1 & OLFL3 & SND1 & WNT5A \\
\hline & ACTN4 & CO5 & H31 & PAI1 & SNED1 & ZA2G \\
\hline & ADA10 & CO5A1 & $\mathrm{H} 4$ & PDC6I & SPTB2 & \\
\hline & AEBP1 & $\mathrm{CO} 5 \mathrm{~A} 2$ & HEP2 & PDIA3 & SPTN1 & \\
\hline & AGRIN & CO6A2 & HS90A & PFKAP & SRCRL & \\
\hline & AHNK & CO7A1 & HS90B & PGK1 & SRGN & \\
\hline & ALDOA & CO9 & HSP7C & PGS1 & SRPX & \\
\hline & AMPN & COEA1 & HTRA1 & PGS2 & SRPX2 & \\
\hline & AMY1 & COFA1 & IF4A1 & PKP1 & SULF1 & \\
\hline & ANT3 & COIA1 & IGHA1 & PLEC & SULF2 & \\
\hline & ANX11 & COMP & ITA3 & PLMN & SYDC & \\
\hline & ANXA1 & CYTA & ITA4 & PLOD1 & SYTC & \\
\hline & ANXA5 & DPYL2 & ITA5 & PLOD3 & TAGL2 & \\
\hline & ANXA6 & DYHC1 & ITAV & PLS1 & TBA1B & \\
\hline & AP2A1 & EF1A1 & ITB1 & PLS3 & TBB4B & \\
\hline & AP2M1 & EF2 & ITIH1 & PPIB & TCPA & \\
\hline ACTC & APLP2 & EHD1 & ITIH3 & PRC2A & ТСРВ & \\
\hline MYH1 & APOA4 & EHD2 & ITIH4 & PRDX1 & TCPD & \\
\hline TAU & AРOB & EMIL1 & KLK7 & PRDX6 & ТСРН & \\
\hline & APOE & ENOA & KPYM & PROF1 & TCPQ & \\
\hline & ARF3 & ENPL & LAMA1 & PSB5 & TCPZ & \\
\hline & ARF4 & EXT1 & LAMA2 & PTX3 & TENA & \\
\hline & ARGI1 & EXT2 & LAMA4 & PXDN & TERA & \\
\hline & ARP2 & F13A & LAMA5 & RAB5C & TGM1 & \\
\hline & ARPC2 & FA5 & LAMP1 & RAB7A & TGM2 & \\
\hline & AT1A1 & FAS & LAMP2 & RAC1 & TGM3 & \\
\hline & ATL1 & FAT1 & LDHA & RACK1 & THBG & \\
\hline & ATS12 & FBLN1 & LDHB & RAN & THRB & \\
\hline & ATS13 & FBN1 & LEG1 & RAP1B & THY1 & \\
\hline & ATX2 & FBX50 & LORI & RB11A & TIG1 & \\
\hline & B4GA1 & FETA & LOXL2 & RHOC & TITIN & \\
\hline & BGH3 & FIBB & LRC17 & RIMB1 & TLN1 & \\
\hline & BMP1 & FILA & LRP1 & RL10A & TPIS & \\
\hline & C1QT3 & FLNA & LTBP1 & RL12 & TPM4 & \\
\hline & C1S & FLNB & LTBP2 & RL13A & TRFE & \\
\hline & CAP1 & FLNC & LYSC & RL27 & TRFL & \\
\hline & CASPE & FPRP & MAMC2 & RL6 & TSN14 & \\
\hline & CATA & FSCN1 & MARCS & RS16 & TSP 1 & \\
\hline & CCD80 & G3P & MFGM & RS3 & TSP 2 & \\
\hline & CD151 & GALK1 & MMP2 & RS4X & TSP 3 & \\
\hline & CD44 & GAS6 & MOES & RS8 & TTYH3 & \\
\hline & CD59 & GBB1 & MOT4 & RSSA & UBA1 & \\
\hline & CD63 & GBG12 & MRC2 & S10A9 & UBB & \\
\hline
\end{tabular}


Table 3. Cont.

\begin{tabular}{|c|c|c|c|c|}
\hline \multicolumn{5}{|c|}{ HIV vs. $H I V+A \beta$} \\
\hline \multirow{2}{*}{$\begin{array}{c}\text { HIV unique } \\
\text { AHNK }\end{array}$} & \multicolumn{4}{|c|}{$\mathrm{HIV}+\mathrm{A} \beta$ unique } \\
\hline & $1433 \mathrm{E}$ & CO8B & MIME & RL3 \\
\hline ARGI1 & $1433 \mathrm{~F}$ & COF1 & MOB1B & RL7 \\
\hline ATX2 & $1433 G$ & COPB2 & MPRI & RL7A \\
\hline B4GA1 & $1 \mathrm{~B} 40$ & COR1A & MRP & RLA0 \\
\hline CASPE & $2 \mathrm{AAA}$ & COR1C & MXRA5 & RS11 \\
\hline CATA & $4 \mathrm{~F} 2$ & CTL1 & MYH16 & RS18 \\
\hline CYTA & ACTC & CTL2 & NDKA & RS2 \\
\hline FBX50 & AK1A1 & CTND1 & NEP & RS20 \\
\hline FILA & AL9A1 & CYFP1 & NIBL1 & RS25 \\
\hline GGCT & ALS & DHX9 & NOTC3 & RS3A \\
\hline HORN & ANGL2 & DSG4 & NRP1 & RS9 \\
\hline IGHA1 & ANGL4 & DX39B & OLM2B & RTN4 \\
\hline $\mathrm{K} 1 \mathrm{C} 13$ & ANM1 & ECM1 & P3H1 & RUVB1 \\
\hline KLK7 & ANR31 & ECM2 & PAMR1 & SC23A \\
\hline LORI & AP1G1 & EEA1 & PARVB & SCUB3 \\
\hline LYSC & AP2B1 & EF1G & PCOC1 & SEM3C \\
\hline MYOF & APOM & EGLN & PDIA1 & SEP11 \\
\hline PLS1 & ARF6 & EHD4 & PDIA6 & SEPT2 \\
\hline PRC2A & ARP3 & EIF3A & PDLI5 & SERA \\
\hline RIMB1 & ARPC4 & EZRI & PGFRB & SLIT2 \\
\hline RL27 & ASSY & FA10 & PGM1 & STOM \\
\hline S10A9 & AT1B3 & FA11 & PIP & SVEP1 \\
\hline SNED1 & ATPA & FBN2 & PLOD2 & SYFB \\
\hline SPB12 & ATPB & FIBG & PP1B & SYHC \\
\hline TGM1 & ATS7 & FRIH & PPIA & SYK \\
\hline TGM3 & B4GT5 & G6PD & PRS23 & SYRC \\
\hline TITIN & BASI & G6PI & PRS8 & SYSC \\
\hline \multirow[t]{24}{*}{ ZA2G } & BASP1 & GANAB & PSA3 & TARSH \\
\hline & BGAL & H13 & PSA6 & TBB2A \\
\hline & C1R & H2A1 & PSD11 & TBB5 \\
\hline & C1TC & H2B1K & PSD12 & TCPE \\
\hline & CAD23 & HGFL & PSD13 & TCPG \\
\hline & CALR & HHIP & PSMD1 & TGFB1 \\
\hline & CAND1 & HMCN1 & PSMD2 & TICN1 \\
\hline & CAPZB & HNRPK & PSMD3 & TIE1 \\
\hline & CAV1 & IGSF8 & PUR6 & TIMP3 \\
\hline & CAZA1 & ILK & PYGB & TS101 \\
\hline & CBPN & IMB1 & PYGL & TSN6 \\
\hline & CCBE1 & IPO5 & QSOX1 & TSN9 \\
\hline & CD9 & IPO7 & RAB10 & TSP4 \\
\hline & CDC42 & IQGA1 & RAB14 & UACA \\
\hline & CEMIP & KCRM & RAB1A & UGDH \\
\hline & CFAH & KR101 & RAB2A & VAT1 \\
\hline & CHIA & KR111 & RALA & VDAC1 \\
\hline & CHSS2 & KRA11 & RELN & VDAC2 \\
\hline & CISY & LAMB2 & RGN & VGFR1 \\
\hline & CLUS & LIS1 & RL14 & XPO1 \\
\hline & CNTN1 & LMNA & RL18 & XPO2 \\
\hline & $\mathrm{CO} 7$ & LRC15 & RL18A & XPP1 \\
\hline & CO8A & LUM & RL22 & XRCC6 \\
\hline & & & & XYLT1 \\
\hline
\end{tabular}


Table 4. Biological processes, KEGG pathways, and PMIDs for the EV surface unique proteins in the control group for the control vs. HIV comparison.

\begin{tabular}{|c|c|c|c|c|}
\hline \multicolumn{5}{|c|}{$\begin{array}{c}\text { Gene Ontology (GO) Terms for Biological Processes } \\
10 \text { Most Significant Results per FDR (for all GO Terms, See Supplemental Table S1A) }\end{array}$} \\
\hline Term description & Obs & Bgr & FDR & Matching proteins in the network \\
\hline Extracellular structure organization & 16 & 339 & $2.01 \times 10^{-10}$ & $\begin{array}{l}\text { APOA4,COMP,FBLN1,FBN1,FBN2,GAS6, } \\
\text { LAMA1,LCAT,LOXL2,MMP2,NID2,PLOD3, } \\
\text { PRDX4,SERPINE1,SULF1,SULF2 }\end{array}$ \\
\hline Extracellular matrix organization & 14 & 296 & $4.25 \times 10^{-9}$ & $\begin{array}{l}\text { COMP,FBLN1,FBN1,FBN2,GAS6,LAMA1, } \\
\text { LOXL2,MMP2,NID2,PLOD3,PRDX4, } \\
\text { SERPINE1,SULF1,SULF2 }\end{array}$ \\
\hline Organonitrogen compound metabolic process & 42 & 5281 & $3.69 \times 10^{-6}$ & $\begin{array}{c}\text { ACLY,AICDA,ALDOA,ANXA1,APOA4,C1S, } \\
\text { CHIA,EEF1G,EXT1,EXT2,F13A1,FBLN1, } \\
\text { FBN1,GAS6,GNB2L1,GPC1,GPC6,GSTP1, } \\
\text { IGF2R,IGLL1,KRT1,LCAT,LDHA,LDHB, } \\
\text { LEPRE1,LOXL2,LRP1,LTBP1,MMP2,MSRB1, } \\
\text { PDIA3,PGD,PGK1,PLOD3,PPIA,PRDX4, } \\
\text { RAB1B,SULF1,SULF2,TGM1,UBB,WNT5A }\end{array}$ \\
\hline Immune response & 22 & 1560 & $6.48 \times 10^{-6}$ & $\begin{array}{l}\text { ACLY,ACTR3,AICDA,ALDOA,ANXA1, } \\
\text { APOA4,C1S,CHIA,FAS,FLNB,GAS6,GSTP1, } \\
\text { IGF2R,IGLL1,KRT1,LRP1,MSRB1,PPIA, } \\
\text { PRDX4,PYGB,RAP1B,WNT5A }\end{array}$ \\
\hline Vesicle-mediated transport & 23 & 1699 & $6.48 \times 10^{-6}$ & $\begin{array}{c}\text { ACLY,ACTR3,ALDOA,ANXA1,ARF3,F13A1, } \\
\text { FERMT3,GAS6,GSTP1,IGF2R,IGLL1,KRT1, } \\
\text { LOXL2,LRP1,PPIA,PRDX4,PYGB,RAB1B, } \\
\text { RAP1B,SERPINE1,TIMP3,UBB,WDR1 }\end{array}$ \\
\hline Regulated exocytosis & 15 & 691 & $6.48 \times 10^{-6}$ & $\begin{array}{l}\text { ACLY,ALDOA,F13A1,FERMT3,GAS6,GSTP1, } \\
\text { IGF2R,KRT1,PPIA,PRDX4,PYGB,RAP1B, } \\
\text { SERPINE1,TIMP3,WDR1 }\end{array}$ \\
\hline Positive regulation of biological process & 42 & 5459 & $6.48 \times 10^{-6}$ & $\begin{array}{l}\text { ACLY,ACTC1,ACTR3,AICDA,ANXA1,APOA4, } \\
\text { C1S,CHIA,CLIC1,FAS,FBLN1,FBN1,FBN2, } \\
\text { FERMT3,FSCN1,GAS6,GNAI2,GNB2L1,GPC1, } \\
\text { GSTP1,IGF2R,IGLL1,KRT1,LDHA,LEPRE1, } \\
\text { LOXL2,LRP1,MMP2,PDIA3,PPIA,RAB1B, } \\
\text { RAP1B,SERPINE1,SRPX2,SULF1,SULF2, } \\
\text { TGM1,THBS4,TIMP3,UBB,WDR1,WNT5A }\end{array}$ \\
\hline
\end{tabular}


Table 4. Cont.

Gene Ontology (GO) Terms for Biological Processes

10 Most Significant Results per FDR (for all GO Terms, See Supplemental Table S1A)

Term description
Anatomical structure development

40

5085

Response to stimulus
7824
FDR

Matching proteins in the network

CTC1,AICDA,ANXA1,APOA4,COMP,EXT1,

EXT2,FAS,FBLN1,FBN1,FBN2,FERMT3,FLNB,

FLNC,FSCN1,GAS6,GNB2L1,GPC1,GSTP1,

IGF2R,KRT1,LDHA,LEPRE1,LOXL2,LRP1,

LTBP1,MMP2,MYL6,PGK1,PLOD3,PRDX4,

RAP1B,SERPINE1,SRPX2,SULF1,SULF2, TGM1,UBB,WDR1,WNT5A

ACLY,ACTC1,ACTR3,AICDA,ALDOA,ANXA1,

APOA4,C1S,CHIA,CLIC1,EEF1G,EXT1,EXT2,

F13A1,FAS,FBLN1,FBN1,FERMT3,FLNB,

FSCN1,GAS6,GNA2,GNB2L1, GPC1,GPC6

LDHA,LOXL2,LRP1,LTBP1,MMP2,

LDHA,LOXL2,LR 1,LTBP1,MMP2,MSRB,

PIA3,PGK1,PLOD3,P PIA,PRDX4,IYGB, TIMP3,UBB,WNT5A

ACLY,ACTR3,AICDA,ANXA1,APOA4,CHIA CLIC1,FAS,FBLN1,FBN1,FBN2,FERMT3, FSCN1,GAS6,GNAI2,GNB2L1,GPC1,GSTP1,

Positive regulation of cellular process

4898

$7.40 \times 10^{-6}$

MMP2,PDIA3,PPIA, RAB1B,RAP1B, SERPINE1,

SRPX2,SULF1,SULF2,TGM1,THBS4,TIMP3,

$$
\text { UBB,WDR1,WNT5A }
$$

\begin{tabular}{ccccc}
\hline & \multicolumn{6}{c}{ KEGG Pathways } & & \\
\hline Term Description & Obs & Bgr & FDR & Matching Proteins in the Network \\
\hline Proteoglycans in cancer & 7 & 195 & 0.00093 & FAS,FLNB,FLNC,GPC1,MMP2,TIMP3,WNT5A \\
\hline Focal adhesion & 6 & 197 & 0.0053 & COMP,FLNB,FLNC,LAMA1,RAP1B,THBS4 \\
\hline Glycolysis / Gluconeogenesis & 4 & 68 & 0.0054 & ALDOA,LDHA,LDHB,PGK1 \\
\hline HIF-1 signaling pathway & 4 & 98 & 0.0155 & ALDOA,LDHA,PGK1,SERPINE1 \\
\hline Cholesterol metabolism & 3 & 48 & 0.0195 & APOA4,LCAT,LRP1 \\
\hline Malaria & 3 & 47 & 0.0195 & COMP,LRP1,THBS4 \\
\hline
\end{tabular}


Table 4. Cont

\begin{tabular}{|c|c|c|c|c|c|}
\hline \multicolumn{6}{|c|}{10 Most Significant PMID Publications per FDR } \\
\hline Term ID & Term Description & Obs & Bgr & FDR & Matching Proteins in the Network \\
\hline PMID:21654676 & $\begin{array}{l}\text { (2011) D-glucuronyl C5-epimerase } \\
\text { suppresses small-cell lung cancer cell } \\
\text { proliferation in vitro and tumour growth } \\
\text { in vivo. }\end{array}$ & 8 & 62 & $1.79 \times 10^{-5}$ & $\begin{array}{l}\text { EXT1,EXT2,FAS,GPC1,GPC6,MMP2, } \\
\text { SERPINE1,TIMP3 }\end{array}$ \\
\hline PMID:22393382 & $\begin{array}{l}\text { (2012) In vitro phenotypic, genomic and } \\
\text { proteomic characterization of a } \\
\text { cytokine-resistant murine Beta-TC3 cell line. }\end{array}$ & 7 & 42 & $2.32 \times 10^{-5}$ & ALDOA,FAS,GSTP1,LDHA,LDHB,PDIA3,PRDX4 \\
\hline PMID:25829250 & $\begin{array}{l}\text { (2015) Insights into the key roles of } \\
\text { proteoglycans in breast cancer biology and } \\
\text { translational medicine. }\end{array}$ & 10 & 156 & $2.32 \times 10^{-5}$ & $\begin{array}{l}\text { EXT1,FBLN1,FBN1,GPC1,GPC6,MMP2,SULF1, } \\
\text { SULF2,TIMP3,WNT5A }\end{array}$ \\
\hline PMID:26779482 & $\begin{array}{l}\text { (2015) The Extracellular Matrix in } \\
\text { Bronchopulmonary Dysplasia: Target and } \\
\text { Source. }\end{array}$ & 7 & 41 & $2.32 \times 10^{-5}$ & FBLN1,FBN1,FBN2,LOXL2,LTBP1,PLOD3,SULF2 \\
\hline PMID:23143224 & $\begin{array}{l}\text { (2013) The biology of the extracellular } \\
\text { matrix: Novel insights. }\end{array}$ & 6 & 28 & $5.53 \times 10^{-5}$ & COMP,FBN1,FBN2,LTBP1,MMP2,TIMP3 \\
\hline PMID:24223867 & $\begin{array}{l}\text { (2013) Lactate-modulated induction of } \\
\text { THBS-1 activates transforming growth factor } \\
\text { (TGF)-beta2 and migration of glioma cells } \\
\text { in vitro. }\end{array}$ & 6 & 31 & $7.90 \times 10^{-5}$ & COMP,LDHA,LDHB,MMP2,SERPINE1,THBS4 \\
\hline PMID:26076122 & $\begin{array}{l}\text { (2015) Interactions of signaling proteins, } \\
\text { growth factors and other proteins with } \\
\text { heparan sulfate: Mechanisms and mysteries. }\end{array}$ & 6 & 31 & $7.90 \times 10^{-5}$ & EXT1,EXT2,GPC1,GPC6,SULF1,SULF2 \\
\hline PMID:20236620 & $\begin{array}{l}\text { (2010) Unraveling the mechanism of elastic } \\
\text { fiber assembly: The roles of short fibulins. }\end{array}$ & 6 & 33 & $8.27 \times 10^{-5}$ & FBLN1,FBN1,FBN2,LOXL2,LTBP1,TIMP3 \\
\hline PMID:20140087 & $\begin{array}{l}\text { (2010) Comprehensive identification and } \\
\text { modified-site mapping of S-nitrosylated } \\
\text { targets in prostate epithelial cells. }\end{array}$ & 8 & 103 & $8.31 \times 10^{-5}$ & $\begin{array}{c}\text { ALDOA,ANXA1,CLIC1,FLNB,FLNC,PDIA3, } \\
\text { PGK1,PLEC }\end{array}$ \\
\hline PMID:27513329 & $\begin{array}{l}\text { (2016) Differential Expression Pattern of } \\
\text { THBS1 and THBS2 in Lung Cancer: Clinical } \\
\text { Outcome and a Systematic-Analysis of } \\
\text { Microarray Databases. }\end{array}$ & 7 & 65 & $8.31 \times 10^{-5}$ & COMP,FBLN1,FBN1,MMP2,NID2,SULF1,THBS4 \\
\hline
\end{tabular}


Table 5. Biological processes and PMIDs for the EV surface unique proteins in the HIV group for the HIV vs. HIV+A $\beta$ comparison.

\begin{tabular}{|c|c|c|c|c|c|}
\hline \multicolumn{6}{|c|}{ Gene Ontology (GO) Terms for Biological Processes } \\
\hline & rm Description & Obs & Bgr & FDR & Matching Proteins in the Network \\
\hline & keleton organization & 5 & 953 & $8.35 \times 10^{-5}$ & ARPC4,CAP1,DNAH8,NIN,TTN \\
\hline Supr & ecular fiber organization & 4 & 383 & 0.00011 & ARPC4,CAP1,NIN,TTN \\
\hline & ilament organization & 3 & 200 & 0.0011 & ARPC4,CAP1,TTN \\
\hline Cellular pr & -containing complex assembly & 4 & 832 & 0.0012 & ARPC4,DNAH8,NIN,TTN \\
\hline Actin pol & ization or depolymerization & 2 & 43 & 0.0031 & ARPC4,CAP1 \\
\hline & in polymerization & 2 & 83 & 0.0058 & ARPC4,NIN \\
\hline & Localization & 5 & 5233 & 0.0296 & ARPC4,CAP1,DNAH8,NIN,TTN \\
\hline \multicolumn{6}{|c|}{ PMID Publications } \\
\hline Term ID & Term Description & Obs & Bgr & FDR & Matching Proteins in the Network \\
\hline PMID:21050039 & $\begin{array}{l}\text { (2010) Titin A-band-specific monoclonal } \\
\text { antibody Tit1 5H1.1. Cellular Titin as a } \\
\text { centriolar protein in non-muscle cells. }\end{array}$ & 2 & 2 & 0.0016 & NIN,TTN \\
\hline PMID:22985877 & $\begin{array}{l}\text { (2012) Epitope of titin A-band-specific } \\
\text { monoclonal antibody Tit1 } 5 \text { H1.1 is } \\
\text { highly conserved in several Fn3 domains } \\
\text { of the titin molecule. Centriole staining } \\
\text { in human, mouse and zebrafish cells. }\end{array}$ & 2 & 6 & 0.0037 & NIN,TTN \\
\hline PMID:26655833 & $\begin{array}{l}\text { (2016) The centrosome is an } \\
\text { actin-organizing centre. }\end{array}$ & 2 & 12 & 0.0081 & ARPC4,NIN \\
\hline PMID:27094867 & $\begin{array}{l}\text { (2016) Mutations in human C2CD3 cause } \\
\text { skeletal dysplasia and provide new } \\
\text { insights into phenotypic and cellular } \\
\text { consequences of altered C2CD3 function. }\end{array}$ & 2 & 27 & 0.027 & NIN,TTN \\
\hline PMID:29255378 & $\begin{array}{l}\text { (2017) The human, F-actin-based } \\
\text { cytoskeleton as a mutagen sensor. }\end{array}$ & 2 & 35 & 0.0353 & DNAH8,TTN \\
\hline
\end{tabular}


Table 6. Biological processes, KEGG pathways, and PMIDs for the EV surface unique proteins in the HIV+A $\beta$ group for the HIV vs. HIV+A $\beta$ comparison.

Gene ontology (GO) Terms for Biological Processes

10 Most Significant Results per FDR (for All GO Terms, See Supplementary Table S2A)

\begin{tabular}{|c|c|c|c|c|}
\hline Term Description & Obs & Bgr & FDR & Matching Proteins in the Network \\
\hline Immune effector process & 18 & 927 & $9.47 \times 10^{-6}$ & $\begin{array}{l}\text { ACLY,ACTR3,AICDA,ALDOA,C1S,CDC42, } \\
\text { GSTP,IGLL1,KPNB1,KRT1,LRP1,PGM1, } \\
\text { PPIA,PRDX6,PYGB,PYGL,RAP1B,WDR1 }\end{array}$ \\
\hline Leukocyte-mediated immunity & 15 & 632 & $9.47 \times 10^{-6}$ & $\begin{array}{c}\text { ACLY,AICDA,ALDOA,C1S,GSTP1,IGLL1, } \\
\text { KPNB1,KRT1,PGM1,PPIA,PRDX6,PYGB, PYGL,RAP1B,WDR1 }\end{array}$ \\
\hline Vesicle-mediated transport & 23 & 1699 & $9.70 \times 10^{-6}$ & $\begin{array}{l}\text { ACLY,ACTR3,ALDOA,ANXA1,ARF3,CDC42, } \\
\text { F13A1,FERMT3,GSTP1,IGLL1,KPNB1,KRT1, } \\
\text { LOXL2,LRP1,PGM1,PPIA,PRDX6,PYGB,PYGL, } \\
\text { RAP1B,SERPINE1,UBB,WDR1 }\end{array}$ \\
\hline Extracellular matrix organization & 11 & 296 & $9.70 \times 10^{-6}$ & $\begin{array}{l}\text { COMP,FBLN1,FBN1,FBN2,LOXL2,MMP2, } \\
\text { NID2,PLOD3,SERPINE1,SULF1,SULF2 }\end{array}$ \\
\hline Regulated exocytosis & 15 & 691 & $1.15 \times 10^{-5}$ & $\begin{array}{l}\text { ACLY,ALDOA,F13A1,FERMT3,GSTP1, } \\
\text { KPNB1,KRT1,PGM1,PPIA,PRDX6, } \\
\text { PYGB,PYGL,RAP1B,SERPINE1,WDR1 }\end{array}$ \\
\hline Response to stimulus & 51 & 7824 & $1.20 \times 10^{-5}$ & $\begin{array}{c}\text { ACLY,ACTC1,ACTR3,AICDA,ALDOA,ANXA1, } \\
\text { C1S,CDC42,CHIA,CLIC1,EEF1G,EXT1,F13A1, } \\
\text { FAS,FBLN1,FBN1,FERMT3,FLNB,FSCN1,GNB2L1, } \\
\text { GPC1,GPC6,GPRC5A,GSTP1,HMCN1,IGLL1, } \\
\text { KPNB1,KRT1,LDHA,LOXL2,LRP1,LTBP1,MMP2, } \\
\text { PDIA3,PGK1,PGM1,PHGDH,PLOD3,PPIA,PRDX2, } \\
\text { PRDX6,PYGB,PYGL,RAP1B,SERPINE1,SULF1, } \\
\text { SULF2,THBS4,UBA1,UBB,WNT5A }\end{array}$ \\
\hline $\begin{array}{l}\text { Negative regulation of cellular response to growth factor } \\
\text { stimulus }\end{array}$ & 8 & 137 & $1.59 \times 10^{-5}$ & FBN1,FBN2,GPC1,LTBP1,SULF1,SULF2,UBB,WNT5A \\
\hline Immune system process & 26 & 2370 & $2.26 \times 10^{-5}$ & $\begin{array}{l}\text { ACLY,ACTR3,AICDA,ALDOA,ANXA1,C1S, } \\
\text { CDC42,CHIA,FAS,FLNB,GPC1,GSTP1,IGLL1, } \\
\text { KPNB1,KRT1,LRP1,PDIA3,PGM1,PPIA,PRDX6, } \\
\text { PYGB,PYGL,RAP1B,UBB,WDR1,WNT5A }\end{array}$ \\
\hline Carbohydrate metabolic process & 12 & 457 & $2.26 \times 10^{-5}$ & $\begin{array}{l}\text { ALDOA,AMY1B,CHIA,EXT1,FBN1,LDHA, } \\
\text { LDHB,PGK1,PGM1,PYGB,PYGL,RGN }\end{array}$ \\
\hline Immune response & 21 & 1560 & $2.26 \times 10^{-5}$ & $\begin{array}{l}\text { ACLY,ACTR3,AICDA,ALDOA,ANXA1,C1S,CHIA, } \\
\text { FAS,FLNB,GSTP1,IGLL1,KPNB1,KRT1,LRP1, } \\
\text { PGM1,PPIA,PRDX6,PYGB,PYGL,RAP1B,WNT5A }\end{array}$ \\
\hline
\end{tabular}


Table 6. Cont

\begin{tabular}{|c|c|c|c|c|}
\hline \multicolumn{5}{|c|}{ KEGG Pathways } \\
\hline Term Description & Obs & Bgr & FDR & Matching Proteins in the Network \\
\hline Glycolysis / Gluconeogenesis & 5 & 68 & 0.00077 & ALDOA,LDHA,LDHB,PGK1,PGM1 \\
\hline Proteoglycans in cancer & 7 & 195 & 0.00077 & CDC42,FAS,FLNB,FLNC,GPC1,MMP2,WNT5A \\
\hline Focal adhesion & 6 & 197 & 0.0035 & CDC42,COMP,FLNB,FLNC,RAP1B,THBS4 \\
\hline Pentose phosphate pathway & 3 & 30 & 0.0068 & ALDOA,PGM1,RGN \\
\hline Starch and sucrose metabolism & 3 & 33 & 0.0071 & PGM1,PYGB,PYGL \\
\hline Metabolic pathways & 13 & 1250 & 0.0095 & $\begin{array}{c}\text { ACLY,ALDOA,CHIA,EXT1,LDHA,LDHB, } \\
\text { PGK1,PGM1,PHGDH,PRDX6,PYGB,PYGL,RGN }\end{array}$ \\
\hline HIF-1 signaling pathway & 4 & 98 & 0.0095 & ALDOA,LDHA,PGK1,SERPINE1 \\
\hline Glucagon signaling pathway & 4 & 100 & 0.0095 & LDHA,LDHB,PYGB,PYGL \\
\hline Malaria & 3 & 47 & 0.0104 & COMP,LRP1,THBS4 \\
\hline Carbon metabolism & 4 & 116 & 0.011 & ALDOA,PGK1,PHGDH,RGN \\
\hline Fluid shear stress and atherosclerosis & 4 & 133 & 0.0164 & GPC1,GSTA5,GSTP1,MMP2 \\
\hline Biosynthesis of amino acids & 3 & 72 & 0.0233 & ALDOA,PGK1,PHGDH \\
\hline Platinum drug resistance & 3 & 70 & 0.0233 & FAS,GSTA5,GSTP1 \\
\hline Necroptosis & 4 & 155 & 0.0233 & FAS,PPIA,PYGB,PYGL \\
\hline Complement and coagulation cascades & 3 & 78 & 0.0251 & C1S,F13A1,SERPINE1 \\
\hline Salmonella infection & 3 & 84 & 0.0288 & CDC42,FLNB,FLNC \\
\hline MAPK signaling pathway & 5 & 293 & 0.0307 & CDC42,FAS,FLNB,FLNC,RAP1B \\
\hline AGE-RAGE signaling pathway in diabetic complications & 3 & 98 & 0.0388 & CDC42,MMP2,SERPINE1 \\
\hline Human papillomavirus infection & 5 & 317 & 0.0388 & CDC42,COMP,FAS,THBS4,WNT5A \\
\hline Propanoate metabolism & 2 & 32 & 0.0405 & LDHA,LDHB \\
\hline Leukocyte transendothelial migration & 3 & 112 & 0.0476 & CDC42,MMP2,RAP1B \\
\hline Primary immunodeficiency & 2 & 37 & 0.0481 & AICDA,IGLL1 \\
\hline
\end{tabular}


Table 6. Cont.

\begin{tabular}{|c|c|c|c|c|c|}
\hline \multicolumn{6}{|c|}{10 Most Significant PMID Publications per FDR } \\
\hline Term ID & Term Description & Obs & Bgr & FDR & Matching Proteins in the Network \\
\hline PMID:23823696 & $\begin{array}{l}\text { (2013) Isobaric Tagging-Based } \\
\text { Quantification for Proteomic Analysis: A } \\
\text { Comparative Study of Spared and } \\
\text { Affected Muscles from mdx Mice at the } \\
\text { Early Phase of Dystrophy. }\end{array}$ & 8 & 42 & $1.26 \times 10^{-6}$ & ACLY,ALDOA,ANXA1,EEF1G,LDHB,PGM1,PPIA,PRDX2 \\
\hline PMID:29250190 & $\begin{array}{l}\text { (2017) Role of exosomes in hepatocellular } \\
\text { carcinoma cell mobility alteration. }\end{array}$ & 7 & 34 & $8.40 \times 10^{-6}$ & ANXA1,CLIC1,FBLN1,LRP1,PPIA,PYGB,PYGL \\
\hline PMID:20140087 & $\begin{array}{l}\text { (2010) Comprehensive identification and } \\
\text { modified-site mapping of S-nitrosylated } \\
\text { targets in prostate epithelial cells. }\end{array}$ & 9 & 103 & $9.47 \times 10^{-6}$ & ALDOA,ANXA1,CLIC1,FLNB,FLNC,KPNB1,PDIA3,PGK1,PLEC \\
\hline PMID:29360750 & $\begin{array}{l}\text { (2018) Proteomic Analysis of Secretomes } \\
\text { of Oncolytic Herpes Simplex } \\
\text { Virus-Infected Squamous Cell Carcinoma } \\
\text { Cells. }\end{array}$ & 7 & 37 & $9.47 \times 10^{-6}$ & ACLY,ANXA1,FBN1,FLNC,FSCN1,MMP2,PRDX2 \\
\hline PMID:26779482 & $\begin{array}{c}\text { (2015) The Extracellular Matrix in } \\
\text { Bronchopulmonary Dysplasia: Target } \\
\text { and Source. }\end{array}$ & 7 & 41 & $1.08 \times 10^{-5}$ & FBLN1,FBN1,FBN2,LOXL2,LTBP1,PLOD3,SULF2 \\
\hline PMID:24142637 & $\begin{array}{l}\text { (2013) Gastric autoantigenic proteins in } \\
\text { Helicobacter pylori infection. }\end{array}$ & 7 & 50 & $2.96 \times 10^{-5}$ & ACTR3,GSTP1,LDHB,PDIA3,PRDX2,PRDX6,WDR1 \\
\hline PMID:26184160 & $\begin{array}{l}\text { (2015) A Review: Proteomics in } \\
\text { Nasopharyngeal Carcinoma. }\end{array}$ & 8 & 83 & $2.96 \times 10^{-5}$ & ANXA1,CLIC1,KRT1,MMP2,PPIA,PRDX2,PRDX6,SERPINE1 \\
\hline PMID:26918450 & $\begin{array}{l}\text { (2016) A nuclear-directed human } \\
\text { pancreatic ribonuclease (PE5) targets the } \\
\text { metabolic phenotype of cancer cells. }\end{array}$ & 8 & 89 & $3.71 \times 10^{-5}$ & ACLY,CLIC1,GPC1,GPC6,LDHA,PGM1,PHGDH,WNT5A \\
\hline PMID:24223867 & $\begin{array}{l}\text { (2013) Lactate-modulated induction of } \\
\text { THBS-1 activates transforming growth } \\
\text { factor (TGF)-beta2 and migration of } \\
\text { glioma cells in vitro. }\end{array}$ & 6 & 31 & $5.98 \times 10^{-5}$ & COMP,LDHA,LDHB,MMP2,SERPINE1,THBS4 \\
\hline PMID:20236620 & $\begin{array}{l}\text { (2010) Unraveling the mechanism of } \\
\text { elastic fiber assembly: The roles of short } \\
\text { fibulins. }\end{array}$ & 6 & 33 & $7.46 \times 10^{-5}$ & FBLN1,FBN1,FBN2,HMCN1,LOXL2,LTBP1 \\
\hline
\end{tabular}


Table 7. PMIDs for the EV total unique proteins in the control group for the control vs. HIV comparison.

\begin{tabular}{|c|c|c|c|c|c|}
\hline \multicolumn{6}{|c|}{ The 10 Most Significant PMID Publications According to FDR } \\
\hline Term ID & Term Description & Obs & Bgr & FDR & Matching Proteins in the Network \\
\hline PMID:19812696 & $\begin{array}{l}\text { (2009) Cancer genomics identifies regulatory gene } \\
\text { networks associated with the transition from } \\
\text { dysplasia to advanced lung adenocarcinomas induced } \\
\text { by c-Raf- } 1 \text {. }\end{array}$ & 3 & 154 & 0.0084 & АCTC1,MAPT,MYH1 \\
\hline PMID:20587776 & $\begin{array}{l}\text { (2010) Mathematical modeling of endocytic actin } \\
\text { patch kinetics in fission yeast: disassembly requires } \\
\text { release of actin filament fragments. }\end{array}$ & 2 & 12 & 0.0086 & ACTC1,MYH1 \\
\hline PMID:25275480 & $\begin{array}{l}\text { (2014) Urethral dysfunction in female mice with } \\
\text { estrogen receptor Beta deficiency. }\end{array}$ & 2 & 10 & 0.0086 & ACTC1,MYH1 \\
\hline PMID:22406440 & $\begin{array}{l}\text { (2012) Deferiprone reduces amyloid-Beta and tau } \\
\text { phosphorylation levels but not reactive oxygen } \\
\text { species generation in hippocampus of rabbits fed a } \\
\text { cholesterol-enriched diet. }\end{array}$ & 2 & 15 & 0.0088 & ACTC1,MAPT \\
\hline PMID:10931867 & $\begin{array}{l}\text { (2000) Distinct families of Z-line targeting modules in } \\
\text { the COOH-terminal region of nebulin. }\end{array}$ & 2 & 25 & 0.0099 & ACTC1,MYH1 \\
\hline PMID:11994316 & $\begin{array}{l}\text { (2002) The NH2-terminal peptide of alpha-smooth } \\
\text { muscle actin inhibits force generation by the } \\
\text { myofibroblast in vitro and in vivo. }\end{array}$ & 2 & 26 & 0.0099 & АCTC1,MYH1 \\
\hline PMID:14557251 & $\begin{array}{l}\text { (2003) Skeletal myosin heavy chain function in } \\
\text { cultured lung myofibroblasts. }\end{array}$ & 2 & 26 & 0.0099 & ACTC1,MYH1 \\
\hline PMID:17908293 & $\begin{array}{l}\text { (2007) Identification of genes differentially expressed } \\
\text { during prenatal development of skeletal muscle in } \\
\text { two pig breeds differing in muscularity. }\end{array}$ & 2 & 52 & 0.0099 & ACTC1,MYH1 \\
\hline PMID:19291799 & $\begin{array}{l}\text { (2009) Fast-twitch sarcomeric and glycolytic enzyme } \\
\text { protein loss in inclusion body myositis. }\end{array}$ & 2 & 36 & 0.0099 & MAPT,MYH1 \\
\hline PMID:19325835 & $\begin{array}{l}\text { (2008) Myosin assembly, maintenance and } \\
\text { degradation in muscle: Role of the chaperone UNC-45 } \\
\text { in myosin thick filament dynamics. }\end{array}$ & 2 & 44 & 0.0099 & ACTC1,MYH1 \\
\hline
\end{tabular}


Table 8. Biological processes, KEGG pathways, and PMIDs for the EV total unique proteins in the HIV group for the control vs. HIV comparison.

\begin{tabular}{|c|c|c|c|c|}
\hline \multicolumn{5}{|c|}{ Gene Ontology (GO) Terms for Biological Processes10 Most Significant Results per FDR (for All GO Terms, See Supplementary Table S4A) } \\
\hline Term Description & Obs & Bgr & FDR & Matching Proteins in the Network \\
\hline Vesicle-mediated transport & 57 & 1699 & $1.02 \times 10^{-18}$ & $\begin{array}{l}\text { ACLY,ACTN1,ACTN4,ALDOA,ANXA1,ANXA11,ANXA5, } \\
\text { AP2A1,AP2M1,APLP2,APOB,APOE,ARF3,ARF4,ARPC2, } \\
\text { CAP1,CD44,CD59,CD63,CD81,EEF2,EHD1,EHD2,F13A1, } \\
\text { FERMT3,FLNA,GAS6,ITIH3,ITIH4,KRT1,LAMP1,LAMP2, } \\
\text { LOXL2,LRP1,MFGE8,MRC2,MVP,MYH9,PKP1,PRDX6, } \\
\text { PTX3,RAB5C,RAB7A,RAC1,RAP1B,SERPINE1,SPTBN1, } \\
\text { SRGN,SRPX,TGM2,THBS1,TLN1,TTN,UBB,VPS35,VWF,WDR1 }\end{array}$ \\
\hline Extracellular structure organization & 28 & 339 & $7.06 \times 10^{-17}$ & $\begin{array}{l}\text { AGRN,APOA4,APOB,APOE,BMP1,CD44,COMP, } \\
\text { DCN,FBLN1,FBN1,GAS6,HTRA1,KLK7,LAMA1, } \\
\text { LAMA2,LAMA4,LAMA5,LOXL2,MMP2,NID1,NID2, } \\
\text { PLOD3,PXDN,SERPINE1,SULF1,SULF2,THBS1,VWF }\end{array}$ \\
\hline Platelet degranulation & 20 & 129 & $2.26 \times 10^{-16}$ & $\begin{array}{c}\text { ACTN1,ACTN4,ALDOA,ANXA5,APLP2,CD63,F13A1, } \\
\text { FERMT3,FLNA,GAS6,ITIH3,ITIH4,LAMP2,SERPINE1, } \\
\text { SRGN,THBS1,TLN1,TTN,VWF,WDR1 }\end{array}$ \\
\hline Regulated exocytosis & 35 & 691 & $1.19 \times 10^{-15}$ & $\begin{array}{c}\text { ACLY,ACTN1,ACTN4,ALDOA,ANXA5,APLP2,CAP1, } \\
\text { CD44,CD59,CD63,EEF2,F13A1,FERMT3,FLNA,GAS6, } \\
\text { ITIH3,ITIH4,KRT1,LAMP1,LAMP2,MVP,PKP1,PRDX6, } \\
\text { PTX3,RAB5C,RAB7A,RAC1,RAP1B,SERPINE1,SRGN, } \\
\text { THBS1,TLN1,TTN,VWF,WDR1 }\end{array}$ \\
\hline Extracellular matrix organization & 25 & 296 & $2.14 \times 10^{-15}$ & $\begin{array}{c}\text { AGRN,BMP1,CD44,COMP,DCN,FBLN1,FBN1,GAS6, } \\
\text { HTRA1,KLK7,LAMA1,LAMA2,LAMA4,LAMA5,LOXL2, } \\
\text { MMP2,NID1,NID2,PLOD3,PXDN,SERPINE1,SULF1, } \\
\text { SULF2,THBS1,VWF }\end{array}$ \\
\hline Cellular component organization & 89 & 5163 & $2.93 \times 10^{-14}$ & $\begin{array}{c}\text { ACTN1,ACTN4,AGRN,ALDOA,ANXA1,ANXA6, } \\
\text { AP2A1,AP2M1,APOA4,APOB,APOE,ARF4,ARPC2, } \\
\text { ATL1,ATXN2,BMP1,CAP1,CD151,CD44,CD59,COMP, } \\
\text { DCN,EHD1,EHD2,EXT1,FAS,FAT1,FBLN1,FBN1, } \\
\text { FERMT3,FLNA,FLNB,FLNC,FSCN1,GAS6,GGCT, } \\
\text { HIST1H4F,HTRA1,KLK7,KRT1,LAMA1,LAMA2, } \\
\text { LAMA4,LAMA5,LAMP2,LOXL2,LTBP2,MFGE8, } \\
\text { MMP2,MSRB1,MYH9,MYOF,NID1,NID2,PKP1, } \\
\text { PLEC,PLOD3,PLS1,PLS3,PTGFRN,PXDN,RAB7A, } \\
\text { RAC1,RAN,RHOC,SDC4,SEMG1,SERPINE1,SGCG, } \\
\text { SLC25A6,SPAG1,SPTBN1,SRGN,SRPX,SULF1, } \\
\text { SULF2,TGM1,TGM2,TGM3,THBS1,THY1,TLN1, } \\
\text { TPM4,TTN,UBB,VPS35,VWF,WDR1,WNT5A }\end{array}$ \\
\hline
\end{tabular}


Table 8. Cont

\begin{tabular}{|c|c|c|c|c|}
\hline \multicolumn{5}{|c|}{ Gene Ontology (GO) Terms for Biological Processes10 Most Significant Results per FDR (for All GO Terms, See Supplementary Table S4A) } \\
\hline Term Description & Obs & Bgr & FDR & Matching Proteins in the Network \\
\hline Secretion by cell & 37 & 959 & $2.43 \times 10^{-13}$ & $\begin{array}{c}\text { ACLY,ACTN1,ACTN4,ALDOA,ANXA1,ANXA5, } \\
\text { APLP2,CAP1,CD44,CD59,CD63,EEF2,F13A1, } \\
\text { FERMT3,FLNA,GAS6,ITIH3,ITIH4,KRT1,LAMP1, } \\
\text { LAMP2,LTBP2,MVP,PKP1,PRDX6,PTX3,RAB5C, } \\
\text { RAB7A,RAC1,RAP1B,SERPINE1,SRGN,THBS1, } \\
\text { TLN1,TTN,VWF,WDR1 }\end{array}$ \\
\hline Response to stimulus & 107 & 7824 & $6.96 \times 10^{-12}$ & $\begin{array}{c}\text { ACLY,ACTN4,AFP,AGRN,AHCY,AICDA,ALDOA, } \\
\text { ANXA1,ANXA11,ANXA5,ANXA6,AP2A1,AP2M1, } \\
\text { APLP2,APOA4,APOB,APOE,ARF4,ARPC2,AZGP1, } \\
\text { C1S,CAP1,CD151,CD44,CD59,CD63,CD81,CD82, } \\
\text { CLIC1,DCN,EEF2,EHD1,EHD2,EXT1,EXT2,F13A1, } \\
\text { FAS,FBLN1,FBN1,FERMT3,FLNA,FLNB,FSCN1, } \\
\text { GAS6,GGCT,GNAI2,GNB2L1,GPC6,GPRC5A, } \\
\text { HIST1H4F,HSPA5,ITIH4,KRT1,LAMA1,LAMA2, } \\
\text { LAMA5,LAMP1,LAMP2,LDHA,LOXL2,LRP1, } \\
\text { LTBP1,LTBP2,MMP2,MRC2,MSRB1,MVP,MYH9, } \\
\text { MYOF,NNMT,PDIA3,PGK1,PKP1,PLOD1,PLOD3, } \\
\text { POLR3G,PRDX1,PRDX6,PTX3,PXDN,RAB5C, } \\
\text { RAB7A,RAC1,RAN,RAP1B,RHOC,SDC4,SEMG1, } \\
\text { SERPINE1,SLC25A6,SPTBN1,SRGN,SRPX,STK33, } \\
\text { SULF1,SULF2,TGM2,THBS1,THRB,THY1,TLN1, } \\
\text { TTN,UBA1,UBB,VPS35,VWF,WNT5A }\end{array}$ \\
\hline Localization & 83 & 5233 & $9.26 \times 10^{-11}$ & $\begin{array}{c}\text { ACLY,ACTN1,ACTN4,AGRN,ALDOA,ANXA1, } \\
\text { ANXA11,ANXA5,ANXA6,AP2A1,AP2M1,APLP2, } \\
\text { APOA4,APOB,APOE,ARF3,ARF4,ARPC2,ATXN2, } \\
\text { AZGP1,CAP1,CD151,CD44,CD59,CD63,CD81, } \\
\text { CLIC1,EEF2,EHD1,EHD2,F13A1,FAT1,FBN1, } \\
\text { FERMT3,FLNA,FLNB,FSCN1,GAS6,GPC6,HSPA5, } \\
\text { ITIH3,ITIH4,KRT1,LAMA5,LAMP1,LAMP2,LOXL2, } \\
\text { LRP1,LTBP1,LTBP2,MFGE8,MRC2,MVP,MYH9, } \\
\text { PKP1,PLOD3,PLS1,PRDX6,PTX3,RAB5C,RAB7A, } \\
\text { RAC1,RAN,RAP1B,RHOC,SDC4,SERPINE1, } \\
\text { SLC25A6,SPTBN1,SRGN,SRPX,SRPX2,TGM2, } \\
\text { THBS1,THY1,TLN1,TTN,TTYH3,UBB,VPS35, } \\
\text { VWF,WDR1,WNT5A }\end{array}$ \\
\hline
\end{tabular}


Table 8. Cont.

\begin{tabular}{|c|c|c|c|c|}
\hline \multicolumn{5}{|c|}{ Gene Ontology (GO) Terms for Biological Processes10 Most Significant Results per FDR (for All GO Terms, See Supplementary Table S4A) } \\
\hline Term Description & Obs & Bgr & FDR & Matching Proteins in the Network \\
\hline Anatomical structure development & 80 & 5085 & $5.90 \times 10^{-10}$ & $\begin{array}{c}\text { ACTN1,AEBP1,AFP,AGRN,AICDA,ANXA1, } \\
\text { AP2A1,APOA4,APOB,APOE,ARF4,ATL1,BMP1, } \\
\text { C6orf58,CAP1,CD151,CD44,COMP,DCN,EEF2, } \\
\text { EHD1,EXT1,EXT2,FAS,FAT1,FBLN1,FBN1, } \\
\text { FERMT3,FLNA,FLNB,FLNC,FSCN1,GAS6, } \\
\text { GNB2L1,HSPA5,HTRA1,KLK7,KRT1,LAMA2, } \\
\text { LAMA5,LDHA,LOXL2,LRP1,LTBP1,MFGE8, } \\
\text { MMP2,MYH9,MYL6,MYOF,NID1,NNMT,PGK1, } \\
\text { PKP1,PLOD1,PLOD3,PLS3,PPIB,PRDX1,RAC1, } \\
\text { RAP1B,RHOC,SDC4,SERPINE1,SGCG,SPTBN1, } \\
\text { SRGN,SRPX2,SULF1,SULF2,TGM1,TGM2,TGM3, } \\
\text { THBS1,THBS3,THRB,THY1,TTN,UBB,WDR1,WNT5A }\end{array}$ \\
\hline \multicolumn{5}{|c|}{ KEGG Pathways } \\
\hline Term Description & Obs & Bgr & FDR & Matching Proteins in the Network \\
\hline Focal adhesion & 17 & 197 & $1.23 \times 10^{-10}$ & $\begin{array}{l}\text { ACTN1,ACTN4,COMP,FLNA,FLNB,FLNC, } \\
\text { LAMA1,LAMA2,LAMA4,LAMA5,RAC1, } \\
\text { RAP1B,THBS1,THBS2,THBS3,TLN1,VWF }\end{array}$ \\
\hline ECM-receptor interaction & 12 & 81 & $5.47 \times 10^{-10}$ & $\begin{array}{l}\text { AGRN,CD44,COMP,LAMA1,LAMA2,LAMA4, } \\
\text { LAMA5,SDC4,THBS1,THBS2,THBS3,VWF }\end{array}$ \\
\hline Proteoglycans in cancer & 12 & 195 & $3.88 \times 10^{-6}$ & $\begin{array}{l}\text { CD44,CD63,DCN,FAS,FLNA,FLNB,FLNC, } \\
\text { MMP2,RAC1,SDC4,THBS1,WNT5A }\end{array}$ \\
\hline Phagosome & 10 & 145 & $1.40 \times 10^{-5}$ & $\begin{array}{l}\text { COMP,LAMP1,LAMP2,MRC2,RAB5C, } \\
\text { RAB7A,RAC1,THBS1,THBS2,THBS3 }\end{array}$ \\
\hline Amoebiasis & 8 & 94 & $4.01 \times 10^{-5}$ & $\begin{array}{c}\text { ACTN1,ACTN4,LAMA1,LAMA2,LAMA4, } \\
\text { LAMA5,RAB5C,RAB7A }\end{array}$ \\
\hline Malaria & 6 & 47 & $8.88 \times 10^{-5}$ & CD81,COMP,LRP1,THBS1,THBS2,THBS3 \\
\hline Salmonella infection & 7 & 84 & 0.00016 & ARPC2,FLNA,FLNB,FLNC,MYH9,RAB7A,RAC1 \\
\hline
\end{tabular}


Table 8. Cont.

\begin{tabular}{|c|c|c|c|c|}
\hline \multicolumn{5}{|c|}{ KEGG Pathways } \\
\hline Term Description & Obs & Bgr & FDR & Matching Proteins in the Network \\
\hline Endocytosis & 10 & 242 & 0.00054 & $\begin{array}{l}\text { AP2A1,AP2M1,ARF3,ARPC2,EHD1,EHD2,RAB5C,RAB7A, } \\
\text { UBB,VPS35 }\end{array}$ \\
\hline Leukocyte transendothelial migration & 7 & 112 & 0.0007 & ACTN1,ACTN4,GNAI2,MMP2,RAC1,RAP1B,THY1 \\
\hline Human papillomavirus infection & 11 & 317 & 0.00079 & $\begin{array}{c}\text { COMP,FAS,LAMA1,LAMA2,LAMA4,LAMA5,THBS1, } \\
\text { THBS2,THBS3,VWF,WNT5A }\end{array}$ \\
\hline PI3K-Akt signaling pathway & 10 & 348 & 0.0069 & $\begin{array}{c}\text { COMP,LAMA1,LAMA2,LAMA4,LAMA5,RAC1,THBS1, } \\
\text { THBS2,THBS3,VWF }\end{array}$ \\
\hline Complement and coagulation cascades & 5 & 78 & 0.0069 & C1S,CD59,F13A1,SERPINE1,VWF \\
\hline Cholesterol metabolism & 4 & 48 & 0.0088 & APOA4,APOB,APOE,LRP1 \\
\hline Toxoplasmosis & 5 & 109 & 0.0226 & GNAI2,LAMA1,LAMA2,LAMA4,LAMA5 \\
\hline Glycolysis / Gluconeogenesis & 4 & 68 & 0.0259 & ALDOA,LDHA,LDHB,PGK1 \\
\hline p53 signaling pathway & 4 & 68 & 0.0259 & CD82,FAS,SERPINE1,THBS1 \\
\hline Platelet activation & 5 & 123 & 0.0308 & FERMT3,GNAI2,RAP1B,TLN1,VWF \\
\hline \multicolumn{5}{|c|}{10 Most Significant PMID Publications per FDR } \\
\hline Term Description & Obs & Bgr & FDR & Matching Proteins in the Network \\
\hline $\begin{array}{l}\text { (2017) Role of exosomes in } \\
\text { hepatocellular carcinoma cell mobility } \\
\text { alteration. }\end{array}$ & 17 & 34 & $1.84 \times 10^{-18}$ & $\begin{array}{l}\text { ACTN1,ANXA1,ANXA11,ANXA5,ANXA6,APOB,APOE, } \\
\text { CAP1,CLIC1,FBLN1,FLNA,ITIH4,LRP1,MFGE8,NID1, } \\
\text { RAN,TLN1 }\end{array}$ \\
\hline $\begin{array}{l}\text { (2012) Quantitative proteomics of } \\
\text { extracellular vesicles derived from } \\
\text { human primary and metastatic } \\
\text { colorectal cancer cells. }\end{array}$ & 21 & 161 & $9.74 \times 10^{-14}$ & $\begin{array}{c}\text { AHCY,ANXA1,ANXA11,ANXA5,ANXA6,ARF3,ARPC2, } \\
\text { CD44,CD63,CD81,FSCN1,KRT1,LAMP1,MFGE8,MYH9, } \\
\text { MYL6,PGK1,PTGFRN,RAB5C,RAB7A,VPS35 }\end{array}$ \\
\hline
\end{tabular}


Table 8. Cont.

\begin{tabular}{|c|c|c|c|c|c|}
\hline \multicolumn{6}{|c|}{10 Most Significant PMID Publications per FDR } \\
\hline Term ID & Term Description & Obs & Bgr & FDR & Matching Proteins in the Network \\
\hline PMID:19948009 & $\begin{array}{l}\text { (2009) Proteomic analysis of blastema } \\
\text { formation in regenerating axolotl } \\
\text { limbs. }\end{array}$ & 22 & 221 & $1.76 \times 10^{-12}$ & $\begin{array}{l}\text { ANXA1,ANXA11,ANXA5,ANXA6,DCN,EEF2,FBN1, } \\
\text { FLNB,GNB2L1,MVP,MYH9,MYL6,MYOF,PDIA3, } \\
\text { PLS3,PRDX1,PXDN,RAN,SND1,TTN,UBA1,WNT5A }\end{array}$ \\
\hline PMID:24392111 & $\begin{array}{l}\text { (2014) Proteomic analysis of C2C12 } \\
\text { myoblast and myotube exosome-like } \\
\text { vesicles: a new paradigm for } \\
\text { myoblast-myotube cross talk? }\end{array}$ & 16 & 79 & $1.87 \times 10^{-12}$ & $\begin{array}{l}\text { ALDOA,ANXA5,CD44,CD63,CD81,CD82,EEF2,FLNC, } \\
\text { LAMP1,LAMP2,LDHA,MYOF,PGK1,TLN1,TTN,VPS35 }\end{array}$ \\
\hline PMID:27605433 & $\begin{array}{l}\text { (2016) Secreted primary human } \\
\text { malignant mesothelioma exosome } \\
\text { signature reflects oncogenic cargo. }\end{array}$ & 17 & 107 & $5.36 \times 10^{-12}$ & $\begin{array}{l}\text { ACLY,ANXA1,ANXA6,CD44,CD63,CD81,CD82,FAT1, } \\
\text { GNB2L1,LAMA1,LAMP1,MFGE8,MMP2,PLS3,SULF1, } \\
\text { THBS1,VPS35 }\end{array}$ \\
\hline PMID:22897585 & $\begin{array}{l}\text { (2012) Rat mammary extracellular } \\
\text { matrix composition and response to } \\
\text { ibuprofen treatment during } \\
\text { postpartum involution by differential } \\
\text { GeLC-MSMS analysis. }\end{array}$ & 13 & 42 & $1.24 \times 10^{-11}$ & $\begin{array}{l}\text { AGRN,ANXA1,ANXA11,ANXA5,ANXA6,CD44,DCN, } \\
\text { FBN1,LAMA1,LAMA2,LAMA4,LAMA5,VWF }\end{array}$ \\
\hline PMID:27770278 & $\begin{array}{l}\text { (2017) Comprehensive proteome } \\
\text { profiling of glioblastoma-derived } \\
\text { extracellular vesicles identifies markers } \\
\text { for more aggressive disease. }\end{array}$ & 14 & 63 & $3.75 \times 10^{-11}$ & $\begin{array}{l}\text { ACTN4,ANXA1,CCT6A,CD44,EHD1,HSPA5,LAMA4, } \\
\text { MMP2,MVP,MYH9,RAB5C,RAB7A,UBA1,VPS35 }\end{array}$ \\
\hline PMID:22159717 & $\begin{array}{l}\text { (2012) The matrisome: in silico } \\
\text { definition and in vivo characterization } \\
\text { by proteomics of normal and tumor } \\
\text { extracellular matrices. }\end{array}$ & 14 & 64 & $3.97 \times 10^{-11}$ & $\begin{array}{l}\text { AGRN,ANXA1,ANXA11,ANXA5,ANXA6,DCN,FBN1, } \\
\text { LOXL2,LTBP2,NID1,NID2,SRPX,THBS1,VWF }\end{array}$ \\
\hline PMID:25201077 & $\begin{array}{l}\text { (2015) Proteomics of apheresis platelet } \\
\text { supernatants during routine storage: } \\
\text { Gender-related differences. }\end{array}$ & 16 & 106 & $5.20 \times 10^{-11}$ & $\begin{array}{l}\text { ACTN1,APOB,APOE,ARPC2,C1S,FERMT3,FLNA,ITIH4, } \\
\text { LDHA,MMP2,MYL6,PRDX6,SRGN,THBS1,TLN1,VWF }\end{array}$ \\
\hline PMID:28071719 & $\begin{array}{c}\text { (2017) Quantitative proteomic profiling } \\
\text { of the extracellular matrix of pancreatic } \\
\text { islets during the angiogenic switch and } \\
\text { insulinoma progression. }\end{array}$ & 13 & 54 & $1.20 \times 10^{-10}$ & $\begin{array}{c}\text { ANXA1,ANXA11,ANXA5,ANXA6,DCN,FBN1,LAMA1, } \\
\text { LAMA2,LAMA4,LAMA5,NID1,NID2,THBS2 }\end{array}$ \\
\hline
\end{tabular}


Table 9. Biological processes and PMIDs for the EV total unique proteins in the HIV group for the HIV vs. HIV+A $\beta$ comparison.

\begin{tabular}{|c|c|c|c|c|c|}
\hline \multicolumn{6}{|c|}{ Gene ontology (GO) Terms for Biological Processes } \\
\hline & Term Description & Obs & Bgr & FDR & Matching Proteins in the Network \\
\hline & Cell envelope organization & 2 & 3 & 0.0017 & TGM1,TGM3 \\
\hline \multicolumn{6}{|c|}{10 Most Significant PMID Publications per FDR } \\
\hline Term ID & Term Description & Obs & Bgr & FDR & Matching Proteins in the Network \\
\hline PMID:22329734 & $\begin{array}{l}\text { (2012) Expression profile of cornified envelope structural } \\
\text { proteins and keratinocyte differentiation-regulating proteins } \\
\text { during skin barrier repair. }\end{array}$ & 3 & 14 & 0.0016 & KLK7,TGM1,TGM3 \\
\hline PMID:11093806 & (2000) Transglutaminase-3, an esophageal cancer-related gene. & 2 & 2 & 0.0136 & TGM1,TGM3 \\
\hline PMID:11562168 & $\begin{array}{l}\text { (2001) Crystallization and preliminary X-ray analysis of human } \\
\text { transglutaminase } 3 \text { from zymogen to active form. }\end{array}$ & 2 & 2 & 0.0136 & TGM1,TGM3 \\
\hline PMID:11980702 & $\begin{array}{l}\text { (2002) Three-dimensional structure of the human } \\
\text { transglutaminase } 3 \text { enzyme: binding of calcium ions changes } \\
\text { structure for activation. }\end{array}$ & 2 & 2 & 0.0136 & TGM1,TGM3 \\
\hline PMID:12850301 & $\begin{array}{l}\text { (2003) Analysis of epidermal-type transglutaminase } \\
\text { (transglutaminase 3) in human stratified epithelia and cultured } \\
\text { keratinocytes using monoclonal antibodies. }\end{array}$ & 2 & 3 & 0.0136 & TGM1,TGM3 \\
\hline PMID:14508061 & $\begin{array}{l}\text { (2003) A model for the reaction mechanism of the } \\
\text { transglutaminase } 3 \text { enzyme. }\end{array}$ & 2 & 2 & 0.0136 & TGM1,TGM3 \\
\hline PMID:14645372 & $\begin{array}{c}\text { (2004) Structural basis for the coordinated regulation of } \\
\text { transglutaminase } 3 \text { by guanine nucleotides and } \\
\text { calciummagnesium. }\end{array}$ & 2 & 2 & 0.0136 & TGM1,TGM3 \\
\hline PMID:14987256 & $\begin{array}{l}\text { (2004) Identification of calcium-inducible genes in primary } \\
\text { keratinocytes using suppression-subtractive hybridization. }\end{array}$ & 2 & 8 & 0.0136 & KLK7,TGM1 \\
\hline PMID:15084592 & $\begin{array}{l}\text { (2004) Crystal structure of transglutaminase } 3 \text { in complex with } \\
\text { GMP: structural basis for nucleotide specificity. }\end{array}$ & 2 & 2 & 0.0136 & TGM1,TGM3 \\
\hline PMID:15172109 & $\begin{array}{l}\text { (2004) Transglutaminase activity and transglutaminase mRNA } \\
\text { transcripts in gerbil brain ischemia. }\end{array}$ & 2 & 3 & 0.0136 & TGM1,TGM3 \\
\hline
\end{tabular}


Table 10. Biological processes, KEGG pathways, and PMIDs for the EV total unique proteins in the HIV+A $\beta$ group for the HIV vs. HIV+A $\beta$ comparison.

Gene Ontology (GO) Terms for Biological Processes

10 Most Significant Results per FDR (for All GO Terms, See Supplementary Table S5A)

\begin{tabular}{|c|c|c|c|c|}
\hline Term Description & Obs & Bgr & FDR & Matching Proteins in the Network \\
\hline Vesicle-mediated transport & 41 & 1699 & $2.01 \times 10^{-13}$ & $\begin{array}{c}\text { ACTR3,AP1G1,AP2B1,ARF6,ARPC4,CALR,CAND1,CAPZB,CAV1, } \\
\text { CD9,CDC42,COPB2,ECM1,EEA1,EHD4,IGF2R,KPNB1,MME,NME1, } \\
\text { PDIA6,PGM1,PPIA,PSMD1,PSMD2,PSMD3,PYGB,PYGL,QSOX1, } \\
\text { RAB10,RAB14,RAB1A,RAB2A,RALA,SLC44A2,SOD1,STOM,SYK, } \\
\text { TGFB1,TIMP3,VAT1,XRCC6 }\end{array}$ \\
\hline Localization & 66 & 5233 & $4.37 \times 10^{-11}$ & $\begin{array}{c}\text { ACTR3,AP1G1,AP2B1,APOM,ARF6,ARPC4,CALR,CAND1,CAPZB, } \\
\text { CAV1,CD9,CDC42,COPB2,CSE1L,DHX9,ECM1,EEA1,EHD4,FBN2, } \\
\text { IGF2R,IGSF8,ILK,IPO5,IPO7,KPNB1,LMNA,MME,NME1,NRP1, } \\
\text { PAFAH1B1,PDIA6,PGM1,PIP,PPIA,PSMD1,PSMD2,PSMD3,PYGB, } \\
\text { PYGL,QSOX1,RAB10,RAB14,RAB1A,RAB2A,RALA,RELN,RNF128, } \\
\text { RPL14,RTN4,SLC3A2,SLC44A1,SLC44A2,SLIT2,SOD1,SPOCK1, } \\
\text { STOM,SYK,TGFB1,THBS4,TIMP3,VAT1,VDAC1,VDAC2,WLS, } \\
\text { XPO1,XRCC6 }\end{array}$ \\
\hline Secretion & 30 & 1070 & $8.12 \times 10^{-11}$ & $\begin{array}{c}\text { CAND1,CAV1,CD9,ECM1,IGF2R,KPNB1,MME,NME1,PAFAH1B1, } \\
\text { PGM1,PPIA,PSMD1,PSMD2,PSMD3,PYGB,PYGL,QSOX1,RAB10, } \\
\text { RAB14,RAB1A,RALA,SLC44A2,SOD1,STOM,SYK,TGFB1,TIMP3, } \\
\text { VAT1,WLS,XRCC6 }\end{array}$ \\
\hline Transport & 57 & 4130 & $1.80 \times 10^{-10}$ & $\begin{array}{c}\text { ACTR3,AP1G1,AP2B1,APOM,ARF6,ARPC4,CALR,CAND1, } \\
\text { CAPZB,CAV1,CD9,CDC42,COPB2,CSE1L,DHX9,ECM1,EEA1, } \\
\text { EHD4,IGF2R,IPO5,IPO7,KPNB1,LMNA,MME,NME1,NRP1, } \\
\text { PAFAH1B1,PDIA6,PGM1,PIP,PPIA,PSMD1,PSMD2,PSMD3, } \\
\text { PYGB,PYGL,QSOX1,RAB10,RAB14,RAB1A,RAB2A,RALA, } \\
\text { RPL14,SLC3A2,SLC44A1,SLC44A2,SOD1,STOM,SYK,TGFB1, } \\
\text { TIMP3,VAT1,VDAC1,VDAC2,WLS,XPO1,XRCC6 }\end{array}$ \\
\hline Secretion by cell & 28 & 959 & $1.80 \times 10^{-10}$ & $\begin{array}{c}\text { CAND1,CD9,ECM1,IGF2R,KPNB1,MME,PAFAH1B1,PGM1, } \\
\text { PPIA,PSMD1,PSMD2,PSMD3,PYGB,PYGL,QSOX1,RAB10, } \\
\text { RAB14,RAB1A,RALA,SLC44A2,SOD1,STOM,SYK,TGFB1, } \\
\text { TIMP3,VAT1,WLS,XRCC6 }\end{array}$ \\
\hline Regulated exocytosis & 24 & 691 & $2.67 \times 10^{-10}$ & $\begin{array}{c}\text { CAND1,CD9,ECM1,IGF2R,KPNB1,MME,PGM1,PPIA,PSMD1, } \\
\text { PSMD2,PSMD3,PYGB,PYGL,QSOX1,RAB10,RAB14,SLC44A2, } \\
\text { SOD1,STOM,SYK,TGFB1,TIMP3,VAT1,XRCC6 }\end{array}$ \\
\hline
\end{tabular}


Table 10. Cont.

Gene Ontology (GO) Terms for Biological Processes

10 Most Significant Results per FDR (for All GO Terms, See Supplementary Table S5A)

\begin{tabular}{|c|c|c|c|c|}
\hline Term Description & Obs & Bgr & FDR & Matching Proteins in the Network \\
\hline Exocytosis & 25 & 774 & $3.25 \times 10^{-10}$ & $\begin{array}{l}\text { CAND1,CD9,ECM1,IGF2R,KPNB1,MME,PGM1,PPIA,PSMD1, } \\
\text { PSMD2,PSMD3,PYGB,PYGL,QSOX1,RAB10,RAB14,RALA, } \\
\text { SLC44A2,SOD1,STOM,SYK,TGFB1,TIMP3,VAT1,XRCC6 }\end{array}$ \\
\hline Neutrophil activation involved in immune response & 19 & 489 & $1.06 \times 10^{-8}$ & $\begin{array}{c}\text { CAND1,IGF2R,KPNB1,MME,PGM1,PPIA,PSMD1,PSMD2, } \\
\text { PSMD3,PYGB,PYGL,QSOX1,RAB10,RAB14,SLC44A2,STOM, } \\
\text { SYK,VAT1,XRCC6 }\end{array}$ \\
\hline Myeloid leukocyte activation & 20 & 574 & $1.48 \times 10^{-8}$ & $\begin{array}{l}\text { CAND1,IGF2R,KPNB1,MME,PGM1,PPIA,PSMD1,PSMD2, } \\
\text { PSMD3,PYGB,PYGL,QSOX1,RAB10,RAB14,SLC44A2,STOM, } \\
\text { SYK,TGFB1,VAT1,XRCC6 }\end{array}$ \\
\hline Neutrophil degranulation & 18 & 485 & $4.95 \times 10^{-8}$ & $\begin{array}{l}\text { CAND1,IGF2R,KPNB1,MME,PGM1,PPIA,PSMD1,PSMD2,PSMD3, } \\
\text { PYGB,PYGL,QSOX1,RAB10,RAB14,SLC44A2,STOM,VAT1,XRCC6 }\end{array}$ \\
\hline \multicolumn{5}{|c|}{ KEGG Pathways } \\
\hline Term description & Obs & Bgr & FDR & Matching Proteins in the Network \\
\hline Endocytosis & 10 & 242 & 0.00016 & AP2B1,ARF6,ARPC4,CAPZB,CAV1,CDC42,EEA1,EHD4,IGF2R,RAB10 \\
\hline Focal adhesion & 8 & 197 & 0.0012 & CAV1,CDC42,ILK,LAMB2,PARVB,PPP1CB,RELN,THBS4 \\
\hline Bacterial invasion of epithelial cells & 5 & 72 & 0.003 & ARPC4,CAV1,CDC42,ILK,SEPT2 \\
\hline Pentose phosphate pathway & 3 & 30 & 0.0278 & G6PD,PGM1,RGN \\
\hline Starch and sucrose metabolism & 3 & 33 & 0.0278 & PGM1,PYGB,PYGL \\
\hline Proteoglycans in cancer & 6 & 195 & 0.0278 & CAV1,CDC42,LUM,PPP1CB,TGFB1,TIMP3 \\
\hline Proteasome & 3 & 43 & 0.0347 & PSMD1,PSMD2,PSMD3 \\
\hline Necroptosis & 5 & 155 & 0.0347 & PPIA,PYGB,PYGL,VDAC1,VDAC2 \\
\hline Fc gamma R-mediated phagocytosis & 4 & 89 & 0.0347 & ARF6,ARPC4,CDC42,SYK \\
\hline Amino sugar and nucleotide sugar metabolism & 3 & 48 & 0.0396 & CHIA,PGM1,UGDH \\
\hline HTLV-I infection & 6 & 250 & 0.0396 & CALR,NRP1,TGFB1,VDAC1,VDAC2,XPO1 \\
\hline
\end{tabular}


Table 10. Cont.

\begin{tabular}{|c|c|c|c|c|c|}
\hline \multicolumn{6}{|c|}{10 Most Significant PMID Publications per FDR } \\
\hline Term ID & Term Description & Obs & Bgr & FDR & Matching Proteins in the Network \\
\hline PMID:11149929 & $\begin{array}{l}\text { (2001) The phagosome proteome: insight } \\
\text { into phagosome functions. }\end{array}$ & 9 & 47 & $3.12 \times 10^{-6}$ & ARF6,CALR,DFFA,P4HB,RAB10,RAB14,RAB2A,STOM,VDAC1 \\
\hline PMID:17892558 & $\begin{array}{l}\text { (2007) Quantifying raft proteins in neonatal } \\
\text { mouse brain by 'tube-gel' protein digestion } \\
\text { label-free shotgun proteomics. }\end{array}$ & 10 & 83 & $6.99 \times 10^{-6}$ & $\begin{array}{l}\text { ACTC1,BASP1,CAV1,CNTN1,RAB10,RAB14,RAB1A,RAB2A, } \\
\text { SLC3A2,VDAC1 }\end{array}$ \\
\hline PMID:22578496 & $\begin{array}{l}\text { (2012) Harnessing the power of the } \\
\text { endosome to regulate neural development. }\end{array}$ & 7 & 35 & 0.00014 & ARF6,EEA1,EHD4,NRP1,RAB14,RTN4,WLS \\
\hline PMID:24009881 & $\begin{array}{l}\text { (2012) Quantitative proteomics of } \\
\text { extracellular vesicles derived from human } \\
\text { primary and metastatic colorectal cancer } \\
\text { cells. }\end{array}$ & 11 & 161 & 0.00014 & $\begin{array}{l}\text { ACTR3,CAPZB,CD9,EHD4,ILK,RAB10,RALA,SLC3A2,SLC44A1, } \\
\text { SYK,UGDH }\end{array}$ \\
\hline PMID:27770278 & $\begin{array}{c}\text { (2017) Comprehensive proteome profiling of } \\
\text { glioblastoma-derived extracellular vesicles } \\
\text { identifies markers for more aggressive } \\
\text { disease. }\end{array}$ & 8 & 63 & 0.00016 & ACTR3,CALR,ECM1,IGF2R,IPO5,PSMD2,RAB10TGFB1 \\
\hline PMID:26205348 & $\begin{array}{l}\text { (2015) Fluoxetine increases plasticity and } \\
\text { modulates the proteomic profile in the adult } \\
\text { mouse visual cortex. }\end{array}$ & 6 & 22 & 0.00023 & AP1G1,CDC42,NME1,SOD1,VDAC1,VDAC2 \\
\hline PMID:20140087 & $\begin{array}{l}\text { (2010) Comprehensive identification and } \\
\text { modified-site mapping of S-nitrosylated } \\
\text { targets in prostate epithelial cells. }\end{array}$ & 9 & 103 & 0.00024 & DHX9,HNRNPK,KPNB1,LMNA,P4HB,PDIA6,RTN4,VDAC1,VDAC2 \\
\hline PMID:27549615 & $\begin{array}{l}\text { (2016) Genome-wide association study to } \\
\text { identify potential genetic modifiers in a } \\
\text { canine model for Duchenne muscular } \\
\text { dystrophy. }\end{array}$ & 6 & 23 & 0.00024 & LMNA,PAMR1,PPIA,PSMD2,SLIT2,THBS4 \\
\hline PMID:23170974 & $\begin{array}{l}\text { (2012) Integrated miRNA, mRNA and } \\
\text { protein expression analysis reveals the role } \\
\text { of post-transcriptional regulation in } \\
\text { controlling CHO cell growth rate. }\end{array}$ & 6 & 27 & 0.00044 & HNRNPK,RAB10,RAB14,RAB1A,RAB2A,RPL14 \\
\hline PMID:24505448 & $\begin{array}{l}\text { (2014) Characterisation of four LIM } \\
\text { protein-encoding genes involved in } \\
\text { infection-related development and } \\
\text { pathogenicity by the rice blast fungus } \\
\text { Magnaporthe oryzae. }\end{array}$ & 6 & 28 & 0.00047 & CDC42,ILK,LMNA,PHGDH,RAB2A,XRCC6 \\
\hline
\end{tabular}


Supplementary Materials: The following are available online at http://www.mdpi.com/1422-0067/21/8/2741/s1.

Author Contributions: Conceptualization, I.E.A. and M.T.; Formal analysis, I.E.A. and B.B.S.; Funding acquisition, M.T.; Investigation, I.E.A. and B.B.S.; Supervision, I.E.A. and M.T.; Visualization, I.E.A.; Writing-original draft, I.E.A.; Writing-review \& editing, M.T. All authors have read and agreed to the published version of the manuscript.

Funding: Supported by the Florida Department of Health grant 8AZ24 and the National Institutes of Health (NIH), grants MH072567, MH098891, HL126559, DA039576, DA040537, DA044579, and DA047157. We acknowledge support from the Miami Center for AIDS Research (CFAR) at the University of Miami Miller School of Medicine, which is funded by a grant (P30AI073961) from the National Institutes of Health (NIH). We would like to thank Joshua Zahner, undergraduate student at the University of Miami, for his help in sorting the unique protein lists.

Conflicts of Interest: The authors declare no conflicts of interest.

\section{Abbreviations}

$\begin{array}{ll}\text { A } \beta & \text { amyloid beta } \\ \text { AD } & \text { Alzheimer's disease } \\ \text { BBB } & \text { Blood-brain barrier } \\ \text { ECGS } & \text { Endothelial cell growth supplement } \\ \text { EV } & \text { Extracellular vesicle } \\ \text { ELISA } & \text { Enzyme-linked immunosorbent assay } \\ \text { HAND } & \text { HIV-associated neurocognitive disorders; } \\ \text { HBMEC } & \text { Human brain microvascular endothelial cells } \\ \text { HEK cells } & \text { Human embryonic kidney cells } \\ \text { HIV } & \text { Human immunodeficiency virus type 1 } \\ \text { PBS } & \text { Phosphate buffered saline } \\ \text { PECAM } & \text { Platelet endothelial cell adhesion molecule } \\ \text { RAGE } & \text { Receptor for advanced glycation end products }\end{array}$

\section{References}

1. Esiri, M.M.; Biddolph, S.C.; Morris, C.S. Prevalence of Alzheimer plaques in AIDS. J. Neurol. Neurosurg. Psychiatry 1998, 65, 29-33. [CrossRef] [PubMed]

2. Rempel, H.C.; Pulliam, L. HIV-1 Tat inhibits neprilysin and elevates amyloid beta. Aids 2005, 19, 127-135. [CrossRef] [PubMed]

3. Xu, J.; Ikezu, T. The comorbidity of HIV-associated neurocognitive disorders and Alzheimer's disease: A foreseeable medical challenge in post-HAART era. J. Neuroimmune Pharmacol. Off. J. Soc. NeuroImmune Pharmacol. 2009, 4, 200-212. [CrossRef] [PubMed]

4. Brew, B.J.; Crowe, S.M.; Landay, A.; Cysique, L.A.; Guillemin, G. Neurodegeneration and ageing in the HAART era. J. Neuroimmune Pharmacol. Off. J. Soc. NeuroImmune Pharmacol. 2009, 4, 163-174. [CrossRef]

5. Achim, C.L.; Adame, A.; Dumaop, W.; Everall, I.P.; Masliah, E.; Neurobehavioral Research, C. Increased accumulation of intraneuronal amyloid beta in HIV-infected patients. J. Neuroimmune Pharmacol. Off. J. Soc. NeuroImmune Pharmacol. 2009, 4, 190-199. [CrossRef] [PubMed]

6. Pulliam, L. HIV regulation of amyloid beta production. J. Neuroimmune Pharmacol. Off. J. Soc. NeuroImmune Pharmacol. 2009, 4, 213-217. [CrossRef]

7. Green, D.A.; Masliah, E.; Vinters, H.V.; Beizai, P.; Moore, D.J.; Achim, C.L. Brain deposition of beta-amyloid is a common pathologic feature in HIV positive patients. Aids 2005, 19, 407-411. [CrossRef]

8. Soontornniyomkij, V.; Moore, D.J.; Gouaux, B.; Soontornniyomkij, B.; Tatro, E.T.; Umlauf, A.; Masliah, E.; Levine, A.J.; Singer, E.J.; Vinters, H.V.; et al. Cerebral beta-amyloid deposition predicts HIV-associated neurocognitive disorders in APOE epsilon4 carriers. Aids 2012, 26, 2327-2335. [CrossRef]

9. Steinbrink, F.; Evers, S.; Buerke, B.; Young, P.; Arendt, G.; Koutsilieri, E.; Reichelt, D.; Lohmann, H.; Husstedt, I.W.; German Competence Network, H.A. Cognitive impairment in HIV infection is associated with MRI and CSF pattern of neurodegeneration. Eur. J. Neurol. 2013, 20, 420-428. [CrossRef]

10. Deane, R.; Zlokovic, B.V. Role of the blood-brain barrier in the pathogenesis of Alzheimer's disease. Curr. Alzheimer Res. 2007, 4, 191-197. [CrossRef] 
11. Vella, L.J.; Sharples, R.A.; Nisbet, R.M.; Cappai, R.; Hill, A.F. The role of exosomes in the processing of proteins associated with neurodegenerative diseases. Eur. Biophys. J. EBJ 2008, 37, 323-332. [CrossRef] [PubMed]

12. Kalani, A.; Tyagi, A.; Tyagi, N. Exosomes: Mediators of neurodegeneration, neuroprotection and therapeutics. Mol. Neurobiol. 2014, 49, 590-600. [CrossRef] [PubMed]

13. Gupta, A.; Pulliam, L. Exosomes as mediators of neuroinflammation. J. Neuroinflammation 2014, 11, 68. [CrossRef] [PubMed]

14. An, K.; Klyubin, I.; Kim, Y.; Jung, J.H.; Mably, A.J.; O’Dowd, S.T.; Lynch, T.; Kanmert, D.; Lemere, C.A.; Finan, G.M.; et al. Exosomes neutralize synaptic-plasticity-disrupting activity of Abeta assemblies in vivo. Mol. Brain 2013, 6, 47. [CrossRef] [PubMed]

15. Yuyama, K.; Sun, H.; Sakai, S.; Mitsutake, S.; Okada, M.; Tahara, H.; Furukawa, J.; Fujitani, N.; Shinohara, Y.; Igarashi, Y. Decreased amyloid-beta pathologies by intracerebral loading of glycosphingolipid-enriched exosomes in Alzheimer model mice. J. Biol. Chem. 2014, 289, 24488-24498. [CrossRef] [PubMed]

16. Yuyama, K.; Sun, H.; Usuki, S.; Sakai, S.; Hanamatsu, H.; Mioka, T.; Kimura, N.; Okada, M.; Tahara, H.; Furukawa, J.; et al. A potential function for neuronal exosomes: Sequestering intracerebral amyloid-beta peptide. FEBS Lett. 2015, 589, 84-88. [CrossRef]

17. Dinkins, M.B.; Dasgupta, S.; Wang, G.; Zhu, G.; He, Q.; Kong, J.N.; Bieberich, E. The 5XFAD Mouse Model of Alzheimer's Disease Exhibits an Age-Dependent Increase in Anti-Ceramide IgG and Exogenous Administration of Ceramide Further Increases Anti-Ceramide Titers and Amyloid Plaque Burden. J. Alzheimer's Dis. JAD 2015, 46, 55-61. [CrossRef]

18. Andras, I.E.; Leda, A.; Contreras, M.G.; Bertrand, L.; Park, M.; Skowronska, M.; Toborek, M. Extracellular vesicles of the blood-brain barrier: Role in the HIV-1 associated amyloid beta pathology. Mol. Cell. Neurosci. 2017, 79, 12-22. [CrossRef]

19. Keerthikumar, S.; Chisanga, D.; Ariyaratne, D.; Al Saffar, H.; Anand, S.; Zhao, K.; Samuel, M.; Pathan, M.; Jois, M.; Chilamkurti, N.; et al. ExoCarta: A Web-Based Compendium of Exosomal Cargo. J. Mol. Biol. 2016, 428, 688-692. [CrossRef]

20. Mathivanan, S.; Fahner, C.J.; Reid, G.E.; Simpson, R.J. ExoCarta 2012: Database of exosomal proteins, RNA and lipids. Nucleic Acids Res. 2012, 40, D1241-D1244. [CrossRef] [PubMed]

21. Wang, Y.; Ledet, R.J.; Imberg-Kazdan, K.; Logan, S.K.; Garabedian, M.J. Dynein axonemal heavy chain 8 promotes androgen receptor activity and associates with prostate cancer progression. Oncotarget 2016, 7, 49268-49280. [CrossRef] [PubMed]

22. Chauveau, C.; Rowell, J.; Ferreiro, A. A rising titan: TTN review and mutation update. Hum. Mutat. 2014, 35, 1046-1059. [CrossRef] [PubMed]

23. Aurivillius, M.; Oymar, K.; Oxelius, V.A. Immunoglobulin heavy G2 chain (IGHG2) gene restriction in the development of severe respiratory syncytial virus infection. Acta Paediatr. 2005, 94, 414-418. [CrossRef] [PubMed]

24. Savas, J.N.; Wang, Y.Z.; DeNardo, L.A.; Martinez-Bartolome, S.; McClatchy, D.B.; Hark, T.J.; Shanks, N.F.; Cozzolino, K.A.; Lavallee-Adam, M.; Smukowski, S.N.; et al. Amyloid Accumulation Drives Proteome-wide Alterations in Mouse Models of Alzheimer's Disease-like Pathology. Cell Rep. 2017, 21, 2614-2627. [CrossRef] [PubMed]

25. Kim, D.K.; Park, J.; Han, D.; Yang, J.; Kim, A.; Woo, J.; Kim, Y.; Mook-Jung, I. Molecular and functional signatures in a novel Alzheimer's disease mouse model assessed by quantitative proteomics. Mol. Neurodegener. 2018, 13, 2. [CrossRef] [PubMed]

26. Andras, I.E.; Eum, S.Y.; Huang, W.; Zhong, Y.; Hennig, B.; Toborek, M. HIV-1-induced amyloid beta accumulation in brain endothelial cells is attenuated by simvastatin. Mol. Cell. Neurosci. 2010, 43, 232-243. [CrossRef] [PubMed]

27. Yu, L.; Petyuk, V.A.; Tasaki, S.; Boyle, P.A.; Gaiteri, C.; Schneider, J.A.; De Jager, P.L.; Bennett, D.A. Association of Cortical beta-Amyloid Protein in the Absence of Insoluble Deposits With Alzheimer Disease. JAMA Neurol. 2019, 76, 818-826. [CrossRef] [PubMed]

28. Macron, C.; Lane, L.; Nunez Galindo, A.; Dayon, L. Deep Dive on the Proteome of Human Cerebrospinal Fluid: A Valuable Data Resource for Biomarker Discovery and Missing Protein Identification. J. Proteome Res. 2018, 17, 4113-4126. [CrossRef] 
29. Pedrero-Prieto, C.M.; Flores-Cuadrado, A.; Saiz-Sanchez, D.; Ubeda-Banon, I.; Frontinan-Rubio, J.; Alcain, F.J.; Mateos-Hernandez, L.; de la Fuente, J.; Duran-Prado, M.; Villar, M.; et al. Human amyloid-beta enriched extracts: Evaluation of in vitro and in vivo internalization and molecular characterization. Alzheimer's Res. Ther. 2019, 11, 56. [CrossRef]

30. Andras, I.E.; Toborek, M. Extracellular vesicles of the blood-brain barrier. Tissue Barriers 2016, 4, e1131804. [CrossRef]

31. Yuyama, K.; Sun, H.; Mitsutake, S.; Igarashi, Y. Sphingolipid-modulated exosome secretion promotes clearance of amyloid-beta by microglia. J. Biol. Chem. 2012, 287, 10977-10989. [CrossRef] [PubMed]

32. Lauren, J.; Gimbel, D.A.; Nygaard, H.B.; Gilbert, J.W.; Strittmatter, S.M. Cellular prion protein mediates impairment of synaptic plasticity by amyloid-beta oligomers. Nature 2009, 457, 1128-1132. [CrossRef] [PubMed]

33. Rauch, S.M.; Huen, K.; Miller, M.C.; Chaudry, H.; Lau, M.; Sanes, J.R.; Johanson, C.E.; Stopa, E.G.; Burgess, R.W. Changes in brain beta-amyloid deposition and aquaporin 4 levels in response to altered agrin expression in mice. J. Neuropathol. Exp. Neurol. 2011, 70, 1124-1137. [CrossRef] [PubMed]

34. Liu, R.M.; van Groen, T.; Katre, A.; Cao, D.; Kadisha, I.; Ballinger, C.; Wang, L.; Carroll, S.L.; Li, L. Knockout of plasminogen activator inhibitor 1 gene reduces amyloid beta peptide burden in a mouse model of Alzheimer's disease. Neurobiol. Aging 2011, 32, 1079-1089. [CrossRef]

35. Bi Oh, S.; Suh, N.; Kim, I.; Lee, J.Y. Impacts of aging and amyloid-beta deposition on plasminogen activators and plasminogen activator inhibitor-1 in the Tg2576 mouse model of Alzheimer's disease. Brain Res. 2015, 1597, 159-167. [CrossRef]

36. Watanabe, N.; Araki, W.; Chui, D.H.; Makifuchi, T.; Ihara, Y.; Tabira, T. Glypican-1 as an Abeta binding HSPG in the human brain: Its localization in DIG domains and possible roles in the pathogenesis of Alzheimer's disease. FASEB J. Off. Publ. Fed. Am. Soc. Exp. Biol. 2004, 18, 1013-1015.

37. Andras, I.E.; Toborek, M. HIV-1 stimulates nuclear entry of amyloid beta via dynamin dependent EEA1 and TGF-beta/Smad signaling. Exp. Cell Res. 2014, 323, 66-76. [CrossRef] [PubMed]

38. Paris, D.; Townsend, K.P.; Obregon, D.F.; Humphrey, J.; Mullan, M. Pro-inflammatory effect of freshly solubilized beta-amyloid peptides in the brain. Prostaglandins Other Lipid Mediat. 2002, 70, 1-12. [CrossRef]

39. Yamada, K.; Hashimoto, T.; Yabuki, C.; Nagae, Y.; Tachikawa, M.; Strickland, D.K.; Liu, Q.; Bu, G.; Basak, J.M.; Holtzman, D.M.; et al. The low density lipoprotein receptor-related protein 1 mediates uptake of amyloid beta peptides in an in vitro model of the blood-brain barrier cells. J. Biol. Chem. 2008, 283, 34554-34562. [CrossRef]

40. Nesvizhskii, A.I.; Keller, A.; Kolker, E.; Aebersold, R. A statistical model for identifying proteins by tandem mass spectrometry. Anal. Chem. 2003, 75, 4646-4658. [CrossRef]

41. Ashburner, M.; Ball, C.A.; Blake, J.A.; Botstein, D.; Butler, H.; Cherry, J.M.; Davis, A.P.; Dolinski, K.; Dwight, S.S.; Eppig, J.T.; et al. Gene ontology: Tool for the unification of biology. The Gene Ontology Consortium. Nat. Genet. 2000, 25, 25-29. [CrossRef] [PubMed]

42. Szklarczyk, D.; Morris, J.H.; Cook, H.; Kuhn, M.; Wyder, S.; Simonovic, M.; Santos, A.; Doncheva, N.T.; Roth, A.; Bork, P.; et al. The STRING database in 2017: Quality-controlled protein-protein association networks, made broadly accessible. Nucleic Acids Res. 2017, 45, D362-D368. [CrossRef] [PubMed]

(C) 2020 by the authors. Licensee MDPI, Basel, Switzerland. This article is an open access article distributed under the terms and conditions of the Creative Commons Attribution (CC BY) license (http://creativecommons.org/licenses/by/4.0/). 